\title{
Systemic Risk and Cross-Sectional Hedge Fund Returns
}

\author{
Inchang Hwang, Simon Xu, Francis In, and Tong Suk Kim ${ }^{\mathrm{d}}$
}

\begin{abstract}
This paper examines the cross-sectional relation between hedge fund returns and systemic risk. Measuring the systemic risk of an individual hedge fund by using the marginal expected shortfall (MES), we find evidence for a positive and statistically significant relation between systemic risk and hedge fund returns. The risk-adjusted return of a hedge fund portfolio with a high systemic risk is $0.64 \%$ per month higher than for one with a low systemic risk during 1994-2012, while negative performance is observed during crisis periods. The relation between systemic risk and hedge fund returns holds for both live and defunct funds. Moreover, the relation holds even after controlling for a large set of fund characteristics. Hence, systemic risk is a powerful determinant of cross-sectional variations in hedge fund returns. Our results imply that the positive relation between hedge fund returns and systemic risk is due to compensation for the realized losses during systemic events.
\end{abstract}

Keywords: hedge fund, systemic risk, cross-section of expected returns JEL Classification: G10, G11, G23, G28, C13

\footnotetext{
${ }^{a}$ Korea Insurance Research Institute, KFPA Bldg, 38 Gukjegeumyung-ro 6-gil, Youngdeungpo-gu, Seoul 07328, South Korea; email hic7217@kaist.ac.kr.

${ }^{\mathrm{b}}$ Department of Banking and Finance, Monash Business School, Monash University, Clayton, VIC 3800, Australia; email simon.xu@monash.edu.

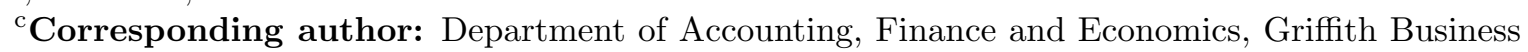
School, Griffith University, Gold Coast campus, QLD 4222, Australia; tel. (+61) 75552 8539; fax (+61) 73735 3719; email f.in@griffith.edu.au.

${ }^{\mathrm{d}}$ Korea Advanced Institute of Science and Technology, College of Business, 85 Hoegiro, Dongdaemoongu, Seoul 130-722, South Korea; email tskim@business.kaist.ac.kr.
} 


\section{Introduction}

The hedge fund industry has been one of the most rapidly growing areas of the financial sector over the last decade. Its rapid growth has resulted from its important benefits to financial markets and investors in the form of improved investment opportunity, price discovery, liquidity, risk sharing, and portfolio diversification. For example, hedge funds have provided funds to build infrastructures in emerging countries over the past years. In spite of these benefits, the role of hedge funds in the financial system has been controversial, because they can be a source of systemic risk to the financial system, potentially exacerbating market failures. ${ }^{1}$ These concerns have especially deepened since the market collapse triggered by Long-Term Capital Management in 1998 and the recent U.S. subprime crisis.

The relation between hedge fund and systemic risk can be described conceptually as the linkage from hedge funds to real economic activity. To be more exact, hedge funds can pose systemic risk by obstructing the ability of financial intermediaries or the financial market to efficiently provide credit through several different mechanisms, or channels (see, e.g., Chan, Getmansky, Haas, \& Lo, 2006; Hildebrand, 2007; Kambhu, Schuermann, \& Stiroh, 2007; McCarthy, 2006). The first channel is the direct risk exposure of financial institutions to hedge funds. Financial intermediaries are directly connected to hedge funds through their counterparty credit risk exposures, as in prime brokerage activity, short-run financing for leveraged positions, and trading counterparty exposures in over-the-counter and other markets. If a bank has a large exposure to a hedge fund that fails or suffers losses on its investments, the increased risk exposure or eroded bank capital may reduce its ability or willingness to provide credit to worthy borrowers. The second channel is disruptions to the efficient functioning of capital markets that impede credit provision. Such disruptions fundamentally reflect a reduced ability or willingness to bear risk through credit provision due to the loss of investor confidence. The third channel is indirect feedback effects of the bank problem in broader financial markets. Because financial intermediaries provide a significant source of liquidity to the hedge fund industry, a shock

\footnotetext{
${ }^{1}$ Although financial stability and systemic risk have become major policy concerns around the world due to the rapid growth in global capital markets and the recent financial crises, systemic risk is not well defined and remains a little vague. Systemic risk usually refers to the risk or probability of collapse of an entire financial system or entire market, as opposed to the risk associated with any individual entity, group, or component of a system (Kaufman, 2000).
} 
induced by hedge funds to financial intermediaries can trigger a chain reaction by reducing the liquidity provision of these banks to other hedge funds or banks, thus leading to financial market disruption.

While there exists a few influential studies on the relation between hedge fund and systemic risk, more studies are warranted on this topic given the economic and regulatory significance of its implications. This paper does not address whether hedge funds pose a significant systemic risk. ${ }^{2}$ Instead, this paper attempts to expand the literature by examining a cross-sectional relation between hedge fund returns and systemic risk. By doing so, this paper provides more insights into the asset allocation and risk management of hedge funds. The primary questions addressed are the following: How is systemic risk related to hedge fund returns? How can we measure the systemic risk contribution of a hedge fund? What is the cross-sectional relation between hedge fund returns and systemic risk? Can the systemic risk contribution of hedge funds explain the cross-sectional variation in hedge fund returns? Is the relation between hedge fund returns and systemic risk affected by fund characteristics related to fund risk, such as age, asset size, fee structure, share restriction, and leverage?

The most common problem with hedge fund research is the short histories of hedge fund returns, less than 20 years on a monthly basis, at the most. Furthermore, systemic events are rare, making it even more difficult to measure systemic risk in the context of hedge funds. This paper employs the marginal expected shortfall (MES) proposed by Acharya, Pedersen, Philippon, and Richardson (2017) and Brownlees and Engle (2017) to measure the systemic risk of individual hedge funds. The MES is defined as the tail expectation of fund returns conditional on systemic events. Acharya et al. (2017) and Brownlees and Engle (2017) propose measures of systemic risk called systemic expected shortfall (SES) and SRISK, respectively. The SES is a linear combination of MES and leverage while the SRISK is a function of MES, leverage, and size. Because there are almost no time series data related to information on hedge fund leverage, it is not possible

\footnotetext{
${ }^{2}$ Contrary to the possible mechanisms, hedge funds may not pose a significant systemic risk because most hedge funds are relatively small, compared to financial institutions such as investment banks, commercial banks, and insurance companies. For example, in our sample, while the mean hedge fund size is $\$ 145.0$ million, the median hedge fund size is only $\$ 44.1$ million. If a large number of hedge funds implement similar strategies, hedge funds may have a significant impact on financial system since they can behave as single giant hedge fund. Even in that case, the amount of capital is relatively modest since hedge funds represent only 1.5\% of the total funds and assets of financial institutions as of 2007 (King \& Maier, 2009).
} 
to construct similar systemic risk indices for hedge funds. As a result, we use only the MES to measure a hedge fund's contribution to systemic risk. Thus, one limitation of our study is that MES is not an exact measure of systemic risk but only a component of the measure of systemic risk. ${ }^{3}$ To alleviate concerns regarding the use of MES in the context of hedge funds, we demonstrate empirically the ability of MES to predict emerging risks of individual hedge funds during the financial crisis. Specifically, the MES predicted fund returns and covariances during the financial crisis to some degree.

Moreover, the measure of systemic risk, MES, applied to hedge funds represents a new way of thinking about tail risk. Although hedge funds are marketed as absolute return or market-neutral investments that generate positive returns in both good and bad market conditions, the hedge fund industry as a whole suffered huge losses during the 1997 Asian currency crisis, the 1998 Russian debt crisis, the 2008 U.S. subprime crisis, and the recent European sovereign debt crisis. Fung and Hsieh (1997, 2001), Mitchell and Pulvino (2001), Agarwal and Naik (2004), and Fung, Hsieh, Naik, and Ramadorai (2008) all show that the dynamic trading and arbitrage strategies implemented by hedge funds generate significant hedge fund tail risk exposure. Brown, Gregoriou, and Pascalau (2012) show that this tail risk exposure may not be diversifiable, which suggests that tail risk can explain hedge fund returns. However, Bali, Brown, and Caglayan (2012) show that tail risk is not important in explaining the cross-sectional variation in hedge fund returns. Whereas Bali et al. (2012) and other studies related to hedge fund tail risk define tail risk as skewness and kurtosis, MES can capture a new type of hedge fund tail risk, defined as the tail expectation of fund returns conditional on systemic events. Especially, MES emphasizes the importance of systemic events (or market failure) as well as dependence between the hedge fund and the market in defining tail risk.

To examine whether the systemic risk contribution of hedge funds plays a role in the cross-sectional variation in hedge fund returns, we measure the systemic risk of a hedge fund and carry out analyses adopted from an asset pricing framework, at both the portfolio level (portfolio-based analysis) and the individual level (regression-based

\footnotetext{
${ }^{3}$ One may argue that a true systemic index for hedge funds should be a function of MES, leverage, and size. However, the focus of our study is not on gauging the systemic risk of hedge funds, but rather examining the cross-sectional relation between the systemic risk contribution of hedge funds and hedge fund returns. Acharya et al. (2017) and Brownlees and Engle (2017) show that SES and SRISK have a significantly positive relation with MES. Therefore, in spite of the potential limitations, our analysis is valid to the extent that MES reflects the systemic risk contribution of hedge funds.
} 
analysis).

Our paper's major findings can be summarized as follows. First, we find that MES can predict the cross section of realized systemic risk contribution of individual hedge funds out-of-sample as measured by the returns of hedge funds and the covariances of hedge funds with the financial system during the financial crisis. Second, we find evidence for a positive and statistically significant relation between the systemic risk contribution of hedge funds measured by the MES and hedge fund returns. The risk-adjusted return of a hedge fund portfolio with a high systemic risk is $0.64 \%$ per month higher than for one with a low systemic risk during 1994-2012, while negative performance is observed during crisis periods. The relation between systemic risk and hedge fund returns holds for both live and defunct funds. Third, the relation between systemic risk and hedge fund returns holds even after controlling for fund characteristics related to fund risk, such as age, asset size, fee structure, share restriction, and leverage, as well as hedge fund style. Furthermore, the relation is not driven by autocorrelation in hedge fund returns.

Our results do not imply that hedge funds are significant systemic risk contributors to the overall financial system. Rather, our findings demonstrate that systemic risk is a powerful determinant of the cross-sectional variations in hedge fund returns. Since hedge funds with high systemic risk exhibit better future performance, our results imply that hedge fund managers have little incentive to reduce systemic risk unless the external costs of systemic risk are internalized by each hedge fund. Our major findings also imply that the positive relation between the systemic risk contribution of hedge funds and hedge fund returns is due to compensation for the realized losses during systemic events. In other words, since MES can also be interpreted as tail risk, these results imply that investors are willing to demand a premium to carry tail risk during systemic events.

The rest of the paper is organized as follows. Section 2 provides a brief review of the literature. Section 3 describes the data set employed and descriptive statistics. Section 4 introduces the methodology, emphasizing the measure of systemic risk. Section 5 presents our empirical results. Section 6 provides additional tests and Section 7 presents our conclusion. 


\section{Literature review}

This paper relates to the recent literature on the risk profile of hedge funds, which has largely focused on explaining cross-sectional relations between expected return, specific risk, and other explanatory hedge fund variables. Fung and Hsieh $(2002,2004)$ and Chan et al. (2006) show that hedge fund returns are nonlinearly related to equity market risk, credit risk, interest rate risk, exchange rate risk, and option-based factors. Bali, Gokcan, and Liang (2007) and Liang and Park (2007) test the presence and significance of a relation between downside risk and expected returns on hedge funds. Buraschi, Kosowski, and Trojani (2014) examine the relation between correlation risk and a cross section of hedge fund returns. Brunnermeier and Pedersen (2009), King and Maier (2009), and Klaus and Rzepkowski (2009) study the role of funding risk related to the interconnectedness of brokers and hedge funds. Sadka (2010) shows that liquidity risk as measured by the covariation of fund returns with unexpected changes in aggregate liquidity explains crosssectional variations in hedge fund returns. Titman and Tiu (2011) find that funds with low $R$-squared values of returns on systematic factors have higher Sharpe ratios, higher information ratios, and higher alphas. Bali, Brown, and Caglayan (2011) examine the performance of hedge fund exposures to various financial and macroeconomic risk factors in predicting cross-sectional variations in hedge fund returns. They find a significantly positive (negative) link between the default premium beta (inflation beta) and future hedge fund returns. Bali et al. (2012) find that systematic risk is highly significant in explaining the dispersion of cross-sectional returns, while measures of residual risk and tail risk seem to have little explanatory power.

Unlike these previous works, we focus on the systemic risk of hedge funds as an important determinant in the cross section of hedge fund returns. In addition, the measure of systemic risk applied in this paper, MES, represents a new way of thinking about tail risk. Whereas Bali et al. (2012) and other studies related to hedge fund tail risk define tail risk as skewness and kurtosis, MES can capture another type of hedge fund tail risk, defined as the tail expectation of fund returns conditional on systemic events. Especially, MES emphasizes the importance of market failure as well as dependence between the hedge fund and the market in defining tail risk.

Moreover, this paper relates to the literature on the systemic risk of hedge funds and 
hedge fund contagion. Chan et al. (2006) develop a number of systemic risk measures for hedge funds based on illiquidity exposure and time-varying hedge fund correlations. Billio, Getmansky, Lo, and Pelizzon (2012) propose several econometric measures of systemic risk to capture the interconnectedness between the finance and insurance sectors, including the hedge fund industry, based on principal component analysis and Granger causality tests. Boyson, Stahel, and Stulz (2010) analyze co-movement between hedge fund style indexes by using quantile regression and logit models and find strong evidence of contagion across hedge fund styles. Whereas these studies largely use aggregate or index hedge fund data to examine whether the entire hedge fund industry or each hedge fund style is related to systemic risk, we focus on individual hedge fund data to use fund-specific information. Lastly, Joenväärä (2009) measures the systemic risk of an individual hedge fund by using the co-expected shortfall approach proposed by Adrian and Brunnermeier (2016). Whereas Joenväärä (2009) examines the relation between hedge fund characteristics and the systemic risk of a hedge fund, we concentrate on the relation between hedge fund returns and the systemic risk contribution of hedge funds measured by the MES, as proposed by Acharya et al. (2017) and Brownlees and Engle (2017).

This paper makes several important contributions to the recent literature on measuring the systemic risk of individual hedge funds. It is the first to measure the systemic risk contribution of a hedge fund by using the MES proposed by Acharya et al. (2017) and Brownlees and Engle (2017) and it provides an example of how the MES can be applied in the context of hedge funds. This paper also contributes to the literature on the risk profiles of hedge funds, none of which has considered the relation between systemic risk and individual hedge fund returns. To the best of our knowledge, this paper is the first to consider the cross-sectional relation between the systemic risk contribution of hedge funds and hedge fund returns in an asset pricing framework. Lastly, this paper contributes to the literature on hedge fund tail risk exposure by stressing the importance of systemic events or market failure in defining tail risk. Although previous works that define tail risk as skewness and kurtosis find that it has little explanatory power for future hedge fund returns, we find that the tail expectation of fund returns conditional on systemic events is highly significant in explaining the dispersion of cross-sectional hedge fund returns. 


\section{Data}

The primary hedge fund database employed in this paper is the Lipper TASS (Trading Advisor Selection System) database, the most commonly utilized database by academics and practitioners in the hedge fund industry. ${ }^{4}$ In addition, we use returns on the valueweighted portfolio of the financial sector as the market return or, more exactly, the return on the financial system. ${ }^{5}$ The TASS database includes 18,862 individual hedge funds from February 1977 to December 2012, of which 7,192 are live and 11,670 defunct. ${ }^{6}$ These data cover more than half of the estimated total number of existing hedge funds. The majority of funds in the TASS database report monthly returns net of management fees, incentive fees, and other fund expenses. Moreover, the TASS database provides other fund-specific information, such as investment strategy, ${ }^{7}$ assets under management (AUM), fee structure, minimum investment, leverage, subscription, redemption, and lockup information.

Hedge fund studies can be subject to data biases (see, e.g., Brown, Goetzmann, Ibbotson, \& Ross, 1992; Edwards \& Caglayan, 2001; Fung \& Hsieh, 2000; Liang, 2000). To deal with potential data biases and to conform to the framework of our analyses in this paper, we apply several restrictions to filter the primary hedge fund database. First, we select the sample period from January 1994 to December 2012 to alleviate any survivorship bias, since the TASS database started tracking defunct funds in 1994 and therefore does not contain information on defunct funds prior to 1994. Second, we select hedge funds that report their returns in U.S. dollars, net of fees, and on a monthly basis. In other words, we eliminate funds that report returns denominated in currencies other than U.S. dollars or gross of fees, as well as funds that report returns on a weekly, quarterly, or annual

\footnotetext{
${ }^{4}$ The TASS database has been used by Fung and Hsieh (1997, 2000), Liang (2000), Brown, Goetzmann, and Park (2001), Lo (2001), Brown and Goetzmann (2003), Agarwal and Naik (2004), Getmansky, Lo, and Makarov (2004), Getmansky, Lo, and Mei (2004), Chan et al. (2006), Bali et al. (2011, 2012, 2007), Kosowski, Naik, and Teo (2007), Agarwal, Daniel, and Naik (2009), and Aggarwal and Jorion (2010), among others.

${ }^{5}$ We thank Kenneth French for providing these data from his website at http://mba.tuck. dartmouth . edu/pages/faculty/ken.french.

${ }^{6}$ The TASS database consists of two parts: live funds and "graveyard" (or defunct) funds. The live funds indicate actively reporting hedge funds as of the most recent database update, December 2012 in our case. By contrast, graveyard funds indicate hedge funds that have stopped reporting to the TASS database due to liquidation, merger, and so forth.

${ }^{7}$ The TASS database classifies funds into 13 categories across different investment strategies: Convertible Arbitrage, Dedicated Short Bias, Emerging Markets, Equity Market Neutral, Event Driven, Fixed Income Arbitrage, Fund of Funds, Global Macro, Long/Short Equity Hedge, Managed Futures, Multi-Strategy, Options Strategy, and Other Strategy.
} 
basis. Third, we concentrate on the following strategies: Convertible Arbitrage, Dedicated Short Bias, Emerging Markets, Equity Market Neutral, Event Driven, Fixed Income Arbitrage, Fund of Funds, Global Macro, Long/Short Equity Hedge, Multi-Strategy, Options Strategy, and Other Strategy. ${ }^{8}$ As of December 2012, these strategies covered 93.9\% of all hedge funds contained in the TASS database. Similar to Bali et al. (2007), we eliminate Managed Futures because we want to focus on individual hedge funds rather than commodity trading advisors. Fourth, to avoid backfill bias, we follow Fung and Hsieh (2000) and omit the first 12-month return histories of all individual hedge funds in our sample. Fifth, we require that each fund have at least 24 months of return history (Bali et al., 2011, 2012; Kosowski et al., 2007) to mitigate the impact of multi-period sampling bias and to estimate a reliable measure of systemic risk. Lastly, we exclude funds that did not report AUM, because we need that information for our analyses.

[Insert Table 1 here]

After these restrictions are all applied, the remaining sample includes 5,771 funds, of which 1,799 are live and 3,972 defunct. Table 1 presents descriptive statistics on the hedge funds' numbers, returns, AUM, and fee structures. Panel A of Table 1 reports, for each year from 1994 to 2012, the number of hedge funds that entered our sample, the number of hedge funds dissolved, total AUM at the end of the year (in billions of U.S. dollars), and the mean, median, standard deviation, minimum, and maximum monthly percentage returns on an equal-weighted hedge fund (EWHF) portfolio. Analyzing Panel A of Table 1 in detail, one can easily observe the sharp reversal in the growth of hedge funds, in both numbers and AUM, since the end of 2007, when the U.S. subprime crisis started to emerge. From 1994 to 2007, the number of hedge funds in our sample increased, on average, by $11.7 \%$ per year (see the column denoted year-end), while the amount of AUM swelled, on average, by $19.9 \%$ per year (see the column denoted total AUM). However, both of these trends went in opposite directions starting in 2008, with the start of the financial crisis, since the number of hedge funds in our sample fell, on average, by $15.2 \%$ per year, while the total AUM dropped, on average, by $21.5 \%$ per year from 2008 to 2012 . These

\footnotetext{
${ }^{8}$ For robustness tests, we also conduct empirical tests in this paper by separately analyzing funds of hedge funds, since recent research indicates that funds of hedge funds should be analyzed separately due to their higher flexibility with respect to their effective investment strategies (Bessler \& Kurmann, 2013; Brown et al., 2012). However, the results are similar and qualitatively unchanged.
} 
two significant shifts in the data highlight how severely the hedge fund industry suffered from the financial crisis over the past few years. In addition, the annual attrition rates in Panel A (the ratio of the number of dissolved funds to the total number of funds at the beginning of the year) also reveal a similar pattern. While the annual attrition rate was, on average, only $4.6 \%$ from 1994 to 2007, it almost tripled to $15.6 \%$ between 2008 and 2012.9

Panel B of Table 1 reports for the sample period 1994-2012 the cross-sectional mean, median, standard deviation, minimum, and maximum statistics for hedge fund characteristics, including returns, size, age, management fees, and incentive fees. One interesting observation that can be extracted from Panel B of Table 1 is the large size disparity seen among hedge funds, where a fund's size is measured as the average monthly AUM over the life of the fund. Based on our sample, while the mean hedge fund size is $\$ 145.0$ million, the median hedge fund size is only $\$ 44.1$ million. This shows the existence of very few hedge funds with very large AUM in the hedge fund industry. Another important aspect of hedge funds is their widespread use of asymmetrical incentive fee structures. Incentive fees are typically a percentage of the fund's annual net profits above a designated hurdle rate and are paid to hedge fund portfolio managers to generate superior performance. The median (mean) incentive fee is $20.0 \%$ (15.14\%) in our sample (which reflects industry standards) and goes up as high as $50.0 \%$ for a few hedge funds. One final interesting characteristic of hedge funds is their short span of life. The median age (number of months in existence since inception) of a fund is only 80 months, even though we require that all hedge funds in the sample have at least 24 months of return history after excluding the first 12 months of returns. The existence of a payout schedule, where hedge fund managers are paid only if they exceed the hurdle rate and must first cover all losses from prior years before getting paid on a current year, forces hedge fund managers to quickly dissolve and form new hedge funds after a bad year (hence the short lifespan), instead of trying to cover those losses in the following years.

\footnotetext{
${ }^{9}$ The restrictions applied to the primary hedge fund database make the reversal patterns more evident. Since we require that all hedge funds in the sample have at least 24 months of return history, after excluding the first 12 months of returns for all hedge funds (to correct for any potential backfill or multi-period sampling bias), only a few funds enter our sample during 2010-2012. However, we also find similar reversal patterns in the growth of hedge funds, in both numbers and AUM, and a sharp increase in the attrition rate, even after including all hedge funds entering our sample in the primary hedge fund database during 2010-2012.
} 


\section{Methodology}

\subsection{Measure of systemic risk}

This section introduces the measure of systemic risk employed in this paper, the MES of Acharya et al. (2017) and Brownlees and Engle (2017). Acharya et al. (2017) present a simple model of systemic risk based on externalities that spill over to the rest of the economy due to undercapitalization of the financial system. Based on the model, they propose an SES - a financial institution's propensity to be undercapitalized when the system as a whole is undercapitalized - as a measure of each financial institution's contribution to systemic risk. The SES increases with the institution's leverage and its MES, which is an expected loss in the tail of the system's loss distribution. However, leverage is hard to use in the context of hedge funds to measure systemic risk, because there are almost no time series data related to information on hedge fund leverage. We therefore use only the MES to measure a hedge fund's contribution to systemic risk. ${ }^{10}$

Here the MES is defined as the marginal contribution of an individual entity to the system's risk. Let $I$ denote the set of individual entities in the system. The return of the entire system can be calculated by the value-weighted average return of all individual entities, which denotes the market return:

$$
r_{m}=\sum_{i \in I} w_{i} r_{i}
$$

where $r_{i}$ and $w_{i}$ are the return and weight in the entire system of entity $i$, respectively. We define a systemic event as a drop in the market return below a threshold $C$. Hence, the systemic event is denoted $\left\{r_{m}<C\right\}$. The expected loss of the entire system conditional on the systemic event $(E L)$ is then

$$
E L(C)=\mathbb{E}\left[r_{m} \mid r_{m}<C\right]=\sum_{i \in I} w_{i} \mathbb{E}\left[r_{i} \mid r_{m}<C\right]
$$

From this equation, we can derive entity $i$ 's MES, which is the marginal contribution of entity $i$ to the overall risk, as the partial derivative of $E L$ with respect to the weight of

\footnotetext{
${ }^{10}$ We also investigate the impact of leverage on our main results. The results are provided in Section 5.3.
} 
entity $i$ in the system:

$$
M E S_{i}(C)=\frac{\partial E L(C)}{\partial w_{i}}=\mathbb{E}\left[r_{i} \mid r_{m}<C\right]
$$

Here the MES measures how entity $i$ 's risk taking adds to the system's overall risk. In brief, the MES can be measured by estimating entity $i$ 's losses when the system as a whole is doing poorly.

Continuing the work of Acharya et al. (2017), who propose a static structural form approach, Brownlees and Engle (2017) propose an alternative dynamic reduced form approach to estimate the measure of systemic risk. As Brownlees and Engle (2017) point out, the dynamic model can better capture dependence and produce more accurate MES predictions than the static model. Moreover, the static approach tends to react to the crises with a substantial delay. For this reason, this paper uses the dynamic reduced form approach proposed by Brownlees and Engle (2017) to estimate the systemic risk of an individual hedge fund.

The econometric approach proposed by Brownlees and Engle (2017) can be summarized as follows. To start, the dynamic reduced form approach specifies the bivariate process of hedge fund and market returns as

$$
\begin{aligned}
& r_{m, t}=\sigma_{m, t} \varepsilon_{m, t} \\
& r_{i, t}=\sigma_{i, t} \rho_{i, t} \varepsilon_{m, t}+\sigma_{i, t} \sqrt{1-\rho_{i, t}^{2}} \xi_{i, t} \\
& \left(\varepsilon_{m, t}, \xi_{i, t}\right) \sim F
\end{aligned}
$$

where $\sigma_{m, t}$ is the conditional standard deviation of the market return, $\sigma_{i, t}$ is the conditional standard deviation of the hedge fund return, $\rho_{i, t}$ is the conditional correlation between the market and hedge fund returns, and $\left(\varepsilon_{m, t}, \xi_{i, t}\right)$ represents the disturbances that drive the system. The disturbances are independent and identically distributed over time and have zero mean, unit variance, and zero covariance. However, they are not assumed independent of each other because extreme values could occur at the same time for systemically risky hedge funds.

The one-period-ahead MES (or ex ante MES) can be expressed as a function of 
volatility, correlation, and tail expectations of the standardized innovation distribution:

$$
\begin{aligned}
M E S_{i, t-1}(C) & =\mathbb{E}_{t-1}\left(r_{i, t} \mid r_{m, t}<C\right) \\
& =\sigma_{i, t} \mathbb{E}_{t-1}\left(\rho_{i, t} \varepsilon_{m, t}+\sqrt{1-\rho_{i, t}^{2}} \xi_{i, t} \mid \varepsilon_{m, t}<C / \sigma_{m, t}\right) \\
& =\sigma_{i, t} \rho_{i, t} \mathbb{E}_{t-1}\left(\varepsilon_{m, t} \mid \varepsilon_{m, t}<C / \sigma_{m, t}\right) \\
& +\sigma_{i, t} \sqrt{1-\rho_{i, t}^{2}} \mathbb{E}_{t-1}\left(\xi_{i, t} \mid \varepsilon_{m, t}<C / \sigma_{m, t}\right) .
\end{aligned}
$$

From Eq. (7), the absolute value of the MES is an increasing function of a hedge fund's own volatility under the assumption that the dependence between the hedge fund and the market is positive. The correlation determines how much weight is given to either the tail expectation of the standardized market residual or the tail expectation of the standardized idiosyncratic hedge fund residual in MES calculations. The second term in Eq. (7) arises since we assume nonlinear dependence in $\left(\varepsilon_{m, t}, \xi_{i, t}\right)$ and it would be zero if the dependence were entirely captured by the correlation. Moreover, the conditioning systemic event $C$ has an important implication because it is unconditional. Typically, the conditioning event of Value at Risk and Expected Shortfall, which are expressed in conditional terms, is a quantile from the conditional return distribution. Hence, while in the conventional approach the probability of observing the conditioning event is constant, in this framework the probability varies with time, i.e., the higher the volatility, the higher the probability of observing a loss above a given threshold. This approach gives us a more flexibility to measure the systemic risk of hedge funds because it allows for time-varying moments and focuses on downside exposure.

To estimate the MES, we adopt a multi-stage modeling approach inspired by the dynamic conditional correlation (DCC) (Engle, 2002, 2009). In the first step, we use GARCH to model volatilities to obtain conditional volatility and standardized residuals. Next, we use a DCC specification to obtain the conditional correlation and standardized idiosyncratic hedge fund residual. Finally, we obtain inference on the tails from flexible methods that allow for potential nonlinear dependence without making specific distributional assumptions. The detailed specifications of volatility, correlation, and tail expectations are available in Appendix A. We report the mean, median, standard deviation, $10 \%$, and $90 \%$ quantiles of the GARCH-DCC model parameter estimates over the full 
sample in Table 2. ${ }^{11}$ In contrast to the sample of financial firms studied in Brownlees and Engle (2017), the dynamics of the hedge funds in our sample exhibit a strong degree of heterogeneity since the coefficient estimates across the GARCH and DCC models fluctuate a fair amount. In particular, for the GARCH model, the $10 \%$ quantile value of $\alpha_{i}^{-}$is negative for our sample but positive for Brownlees and Engle's (2017) implying that some hedge funds in our sample respond in the opposite direction to negative shocks. Turning to the DCC model, the $90 \%$ quantile value for $1-a-b$ is one and the $10 \%$ quantile values for $a$ and $b$ are both zero. This result means that some hedge funds in our sample have no time-varying correlation with the market possibly due to the absolute alpha strategies that they employ.

[Insert Table 2 here]

\subsection{Portfolio-based analysis}

To investigate the cross-sectional relation between hedge fund returns and systemic risk, we use the portfolios of individual hedge funds. The portfolio formation process is adopted from Fama and French (1992), except for the sorting criteria and frequency of portfolio updates. In each month, starting from January 1999, we form 10 decile portfolios of hedge funds based on their MES rank. Funds are kept in the portfolios for one month, that is, we update the portfolios monthly. We use equal-weighted portfolios with an equal number of funds in each portfolio. ${ }^{12}$ In any given month, we include only funds with at least 24 months of return observations to estimate reliable MESs and calculate the MES of each fund using all non-missing past return observations. We therefore have 168 monthly observations (from January 1999 to December 2012) for the 10 equal-weighted portfolios formed based on their MES. We generate these portfolios for both live and defunct funds and then calculate their next month's returns.

Since portfolios 1 and 10 have the lowest and highest average MES values, respectively, we examine the presence and significance of a cross-sectional relation between hedge fund returns and systemic risk using the difference of the one-month-ahead risk-adjusted

\footnotetext{
${ }^{11}$ The coefficient estimates of the GARCH and DCC models are based on Eqs. (11) and (14), respectively, in Appendix A.

${ }^{12}$ For robustness tests, we also conduct empirical tests in this paper by using a value-weighted hedge fund portfolio instead of an equally-weighted hedge fund portfolio. The results are similar and qualitatively unchanged.
} 
returns between these two portfolios. To compute risk-adjusted portfolio returns, we use Fung and Hsieh's (2004) seven-factor model, the most widely used factor model in hedge fund literature. Fung and Hsieh (2004) propose an asset-based style factor model using seven risk factors to explain the risk of well-diversified portfolios of hedge funds. The Fung-Hsieh seven factors include two equity-oriented risk factors (the equity market factor and the size spread factor), two bond-oriented risk factors (the bond market factor and the credit spread factor), and three trend-following risk factors of Fung and Hsieh (2001) on bonds, currencies, and commodities. ${ }^{13}$ We simply regress the monthly portfolio returns sorted by MES on the seven hedge fund factors and then use the intercepts of this regression, called the Fung-Hsieh alpha, as the risk-adjusted portfolio returns.

\subsection{Regression-based analysis}

Previous literature on the risk profiles of hedge funds shows that the cross section of hedge fund returns is related to fund characteristics such as age, asset size, fee structure, share restriction, and leverage (see, e.g., Ackermann, McEnally, \& Ravenscraft, 1999; Agarwal et al., 2009; Aggarwal \& Jorion, 2010; Aragon, 2007; Bali et al., 2007; Boyson, 2008; Edwards \& Caglayan, 2001; Getmansky, Lo, \& Makarov, 2004; Goetzmann, Ingersoll, \& Ross, 2003; Liang, 1999). Hence, to examine the actual underlying relation between systemic risk and hedge fund returns, we must control for fund characteristics related to hedge fund returns. In other words, the relation between systemic risk and hedge fund returns can be affected by these fund characteristics.

Although portfolio-based analysis in Section 4.2 makes it easy to mimic the risk factor in returns related to the MES, this approach does not take into account fund-specific information. To consider the importance of risk factors and fund-specific information

\footnotetext{
${ }^{13}$ The equity market factor is measured by the Standard \& Poor's 500 index monthly total return. The size spread factor is measured by the Russell 2000 index monthly total return less the Standard \& Poor's 500 monthly total return. The bond market factor is measured by the monthly change in the 10-year Treasury constant-maturity yield. The credit spread factor is measured by the monthly change in Moody's Baa yield less the 10-year Treasury constant-maturity yield. The trend-following factors, the so-called "primitive trend following strategies" based on the work of Fung and Hsieh (2001), are calculated by the monthly returns of the portfolios of look-back options (on long-term bonds, currencies, and commodities). We thank David A. Hsieh for providing his risk factors on his website at https://faculty.fuqua.duke.edu/ dah7/HFData.htm.
} 
simultaneously, we run panel regression for the following econometric specification:

$$
\begin{aligned}
R_{i, t+1} & =\alpha_{t}+\beta_{1, t} \operatorname{MES}_{i, t}+\beta_{2, t} A G E_{i, t}+\beta_{3, t} S I Z E_{i, t} \\
& +\beta_{4, t} M G M T F E E_{i}+\beta_{5, t} I_{C T F E E_{i}}+\beta_{6, t} R E D E M P_{i} \\
& +\beta_{7, t} M I N I N V E S T_{i}+\beta_{8, t} D L O C K U P_{i} \\
& +\beta_{9, t} D L E V E R A G E_{i}+\varepsilon_{i, t+1},
\end{aligned}
$$

where $R_{i, t+1}$ is the excess return on fund $i$ in month $t+1$ and $M E S_{i, t}$ is the MES for fund $i$ in month $t$. The variables AGE, SIZE, MGMTFEE, ICTFEE, REDEMP, MININVEST, DLOCKUP, and DLEVERAGE are the fund characteristics: AGE is age measured as the number of months in existence since inception; SIZE is asset size measured as monthly AUM in billions of dollars; MGMTFEE is the management fee, which is a fixed percentage fee on AUM, typically 1-2\%; ICTFEE is the incentive fee, which is a fixed percentage fee of the fund's annual net profits above a designated hurdle rate; REDEMP is the redemption notice period, which is the minimum number of days in advance an investor needs to notify a hedge fund before redeeming a fund's invested amount; MININVEST is the minimum initial investment amount (measured in millions of dollars in the regression) the fund requires from its investors to invest in a fund; DLOCKUP is the dummy variable for lockup provisions (one if the fund prevents investors from withdrawing initial investments for a pre-specified term, usually 12 months, and zero otherwise); and DLEVERAGE is the dummy variable for leverage (one if the fund uses leverage and zero otherwise). Since the residuals may be correlated across funds or across time, we calculate $t$-statistics based on the standard errors clustered by fund and time (month). ${ }^{14}$

\footnotetext{
${ }^{14}$ Many papers use the Fama-MacBeth procedure (Fama \& MacBeth, 1973) in the presence of the within-cluster correlation. Since the Fama-MacBeth standard errors can be biased if the residuals of a given fund are correlated across months for a given fund (time-series dependence), we use standard errors clustered by fund and time (month). For more detailed information, refer to Petersen (2009). Also, the main empirical results are similar and qualitatively unchanged even though we use the Fama-MacBeth standard errors instead of standard errors clustered by fund and time (month).
} 


\section{Empirical results}

\subsection{MES analysis}

In this section, we analyze the MES obtained from the methodology introduced in Section 4.1. We first examine the dynamics of a hedge fund's risk and interdependence during 1999-2012 using the in-sample MES. This analysis also provides the time series properties of the MES over the sample period. Then we investigate whether MES can predict systemic risk realizations in the context of hedge funds, using an out-of-sample prediction exercise over crisis periods.

[Insert Fig. 1 here]

To understand the dynamics of the risk and interdependence of the overall hedge fund industry, we calculate the in-sample MES for an EWHF portfolio in the sample. Panels A and B of Fig. 1 show the return and volatility, respectively. The volatility of the EWHF portfolio is relatively low and stable during the pre-crisis period. Starting in mid-2008, volatility dramatically increases and it peaks in November 2008, after the Lehman bankruptcy. It then starts to decline until mid-2011, dropping to almost the same level as before the crisis. However, volatility increases after mid-2011 as the European sovereign debt crisis emerged. Panel $\mathrm{C}$ of Fig. 1 displays the correlation. Unlike the volatility depicted in Panel B, the correlation is moderately high by historical standards during the pre-crisis period, ranging between 0.4 and 0.8. After Lehman's bankruptcy (September 2008), the correlation increases and maintain a high level until the end of the sample period. Panel D of Fig. 1 reports the MES for various thresholds $C$. The overall MES trend is similar across the different thresholds, while the average MES levels differ from each other. All MESs suddenly collapse at the beginning of the U.S. subprime and European sovereign debt crises. The series start to drop in mid-2008, reaching their minimums in November 2008. The MESs then start to increase until mid-2011, attaining pre-crisis levels. However, after mid-2011, the European sovereign debt crisis triggers a steep decrease that parallels the surge in volatility.

Next, we investigate whether the ex ante MES predicts the out-of-sample cross section of systemic risk realizations in the context of hedge funds over the crisis periods. To determine 
out-of-sample performance, we need a measure of realized systemic risk contribution. Following Adrian and Brunnermeier (2016), Acharya et al. (2017), and Brownlees and Engle (2017), as a proxy we use the returns of hedge funds and the covariances of hedge funds with the financial system during the financial crisis. We estimate the crisis return and crisis covariance as the realized return and realized covariance for September to November 2008 (the U.S. subprime crisis) and July to September 2011 (the European sovereign debt crisis). In the case of the crisis covariance, we also use the realized covariance over one year from the start of each crisis, since a three-month period is too short to estimate the covariance. Then, we use the MES estimated with data as of August 2008 and June 2011 to predict the cross section of the crisis return and crisis covariance for the U.S. subprime crisis and European sovereign debt crisis, respectively. The MES is estimated under a threshold $C$ equal to $-10 \%$, which corresponds approximately to the $5 \%$ quantile of the empirical unconditional market return distribution over the sample period. ${ }^{15}$

\section{[Insert Table 3 here]}

Table 3 presents the coefficients from the regression of the realized crisis return/covariance on the ex ante MES for individual hedge funds. For the prediction test of the crisis return, the MES coefficient is positive and highly statistically significant for both the U.S. subprime and European sovereign debt crises. In other words, systemically risky hedge funds (hedge funds with a low MES) tend to have low returns during the financial crisis. In addition, the MES explains $12 \%$ and $36 \%$ of the cross-sectional crisis returns during the U.S. subprime and European sovereign debt crises, respectively. For the prediction test of the crisis covariance, the MES coefficient is negative and highly statistically significant for both the U.S. subprime and European sovereign debt crises. This result means that systemically risky hedge funds (hedge funds with a low MES) tend to have high covariance with the financial system during the financial crisis. Moreover, the MES explains 20\% and $49 \%$ of the cross-sectional crisis covariance (calculated over one year) during the U.S. subprime and European sovereign debt crises, respectively.

To provide further evidence on the predictive ability of the MES, we construct an aggregate MES index over the whole hedge fund sample and assess whether changes in the aggregate MES index can predict changes in the real economy. Following Allen, Bali,

\footnotetext{
${ }^{15}$ The empirical results in Table 3 are robust to the choice of the threshold $C$.
} 
and Tang (2012), we use the Chicago Fed National Activity Index (CFNAI) to measure the U.S. aggregate economy. The CFNAI is a monthly index designed to gauge overall economic activity and related inflationary pressure. It is a weighted average of 85 monthly indicators of national economic activity. It is constructed to have an average value of zero and a standard deviation of one. Since economic activity tends toward trend growth rate over time, a positive index reading corresponds to growth above trend and a negative index reading corresponds to growth below trend. We use similar control variables to Allen et al. (2012) but adapt them to hedge funds since Allen et al. (2012) study financial firms. We estimate the following $n$-month-ahead predictive regressions of CFNAI on aggregate MES (called $A M E S$ ) with a set of macroeconomic and financial control variables as well as one-month to twelve-month lags of the CFNAI index:

$$
C F N A I_{t+n}=\alpha+\gamma A M E S_{t}+\beta X_{t}+\sum_{i=1}^{12} \lambda_{i} C F N A I_{t-i+1}+\varepsilon_{t+n},
$$

where $A M E S_{t}$ is the aggregate MES calculated as the equal-weighted average of all hedge funds' MES and $X_{t}$ denotes a vector of the following control variables: $D E F$ is the difference between the BAA-rated and AAA-rated corporate bonds; TERM is the difference between the ten-year T-bond and one-month T-bill yields; $R R E L$ is the difference between the one-month T-bill rate and its twelve-month backward-moving average; $H F_{-} R E T$ is the equal-weighted average excess returns of all hedge funds; $H F_{-} V O L$ is the rolling monthly volatility of excess returns of all hedge funds over the past five years; $H F \_S K E W$ is the rolling monthly skewness of excess returns of all hedge funds over the past five years; $H F \_B E T A$ is the average market beta of all hedge funds estimated from monthly returns over the past five years; $M K T \_R E T$ is the monthly excess return on the CRSP value-weighted index; $M K T_{-} V O L$ is the realized monthly volatility of excess returns of the aggregate stock market portfolio; $C O R R$ is the average correlation between excess returns on individual hedge funds and excess returns on the financial market index over the past five years; and $S I Z E$ is the natural logarithm of the monthly AUM of hedge funds.

[Insert Table 4 here] 
Table 4 presents the coefficients from the $n$-month-ahead predictive regressions of CFNAI on AMES where $n$ ranges from 1 to $12 .{ }^{16}$ For brevity, the coefficient estimates for the twelve lags of the dependent variable $\left(C F N A I_{t+n}\right)$ are omitted. Newey-West $t$-statistics are reported in the parenthesis. ${ }^{17}$ The sample period is from January 1994 to December 2012. The results indicate that after controlling for a wide range of factors, the coefficient of $A M E S$ is negative and statistically significant for $n=2$ to 12 , thereby predicting the CFNAI index up to twelve months in advance. ${ }^{18}$ From the two- to twelvemonth-ahead prediction of the CFNAI index, the coefficient estimates of AMES range between -11.16 and -31.11 , and are significant at the $1 \%$ level. The adjusted $R^{2}$ values range between $53 \%$ to $71 \%$. The partial $R^{2}$ values associated with each variable are reported in the brackets. The partial $R^{2}$ of a variable represents the additional percent of the variation of CFNAI that it can explain, conditional on all the other control variables in the regression model that are not lags of CFNAI. Table 4 shows that the variables $A M E S$ and $R R E L$ have the highest partial $R^{2}$ values across all predictive horizons. In particular, the partial $R^{2}$ of $A M E S$ is greater than that of $R R E L$ for $n=4$ to 12 , indicating that the majority of the variation in CFNAI can be explained by changes in $A M E S$. In summary, the findings from Table 4 demonstrate that systemic risk in the hedge fund sector strongly predicts real economic downturns about two to twelve months into the future.

\subsection{Portfolio-based analysis}

\section{[Insert Table 5 here]}

Table 5 reports the cross-sectional relation between the MES and expected returns. To examine whether the cross-sectional relation between the MES and expected returns of defunct funds differs from that between the MES and expected returns of live funds, we form portfolios that use all funds, as well as live and defunct funds separately. This table presents the average monthly risk-adjusted return for each MES portfolio for all, live,

\footnotetext{
${ }^{16}$ Using the augmented Dickey-Fuller test, we reject the null hypothesis that the CFNAI time series has a unit root. The stationary nature of CFNAI minimizes the possibility of spurious predictive regressions.

${ }^{17}$ Following Andrews and Monahan (1992), we compute the lag selection parameter for the standard Newey-West estimate as $\left\lfloor(4 T / 100)^{2 / 9}\right\rfloor$ where $T$ is the sample size and $\lfloor x\rfloor$ is the largest integer less than or equal to $x$.

${ }^{18}$ Although $A M E S$ is not statistically significant for $n=1$, this is most likely due to the multicollinearity problem since some control variables are highly correlated with each other. To alleviate this concern, in unreported tests, we find that $A M E S$ is statistically significant for $n=1$ without the inclusion of $C O R R$ and SIZE.
} 
and defunct funds. When we calculate the MES of each hedge fund, we do not perform any sign conversion. Thus a significantly negative MES value suggests that a specific group of funds poses a significant systemic risk or has a high systemic risk. Table 5 also reports the average size of the MES portfolio as the monthly AUM in billions of dollars. The last column of Table 5 shows the average alpha difference between deciles 1 (low-MES portfolio) and 10 (high-MES portfolio). Newey-West $t$-statistics are reported in the parenthesis.

The expected risk-adjusted returns across different MES portfolios in Table 5 indicate a positive relation between systemic risk measured by the MES and hedge fund return. From deciles 1 to 10, the expected risk-adjusted returns decrease almost monotonically. The highest alpha ( $0.69 \%$ per month) and the lowest ( $0.04 \%$ per month) correspond to the low-MES portfolio (-12.95\% per month) and the high-MES portfolio (3.98\% per month), respectively. Moreover, the last column in Table 5 shows that the average alpha difference between deciles 1 and 10 is positive and statistically significant. The average alpha difference between portfolios 1 and 10 is $0.64 \%$ per month (or $7.68 \%$ per annum), with a Newey-West $t$-statistic of 2.92. This result means that if one invests in the low-MES portfolio while short-selling the high-MES portfolio, one will achieve an annual risk-adjusted profit of $7.68 \%$.

The positive relation between the systemic risk contribution of hedge funds measured by the MES and hedge fund returns may be driven by either only live or defunct funds. To examine the impact of the difference in fund characteristics between live and defunct funds on the relation between systemic risk and hedge fund returns, we investigate the relation using live and defunct funds separately. In addition, Bali et al. (2007) and Fung and Hsieh (2009) emphasize the importance of differentiating between missing and liquidated funds among defunct funds. Due to the nature of voluntary disclosure, funds in the graveyard database are not necessarily all liquidated funds. For example, successful funds as well as failed funds are also more likely to withdraw from the TASS database because they no longer need investors and want to keep away from the public. For this reason, we also investigate the cross-sectional relation between the systemic risk contribution of hedge funds and hedge fund returns using only liquidated funds. ${ }^{19}$

\footnotetext{
${ }^{19}$ The TASS database provides one of eight distinct reasons for a fund being assigned to the graveyard: fund liquidated, fund no longer reporting, unable to contact fund, fund closed to new investment, fund merged into another entity, program closed, fund dormant, and unknown.
} 
Table 5 shows that, regardless of whether a fund is live or defunct, the cross-sectional relation between systemic risk measured by the MES and the expected returns on hedge funds is positive and statistically significant. In the case of live funds, the average alpha difference between portfolios 1 and 10 is $0.82 \%$ per month, with a $t$-statistic of 3.19 . The relation for defunct funds is a little weaker than that for live funds. The average alpha difference between the two extreme portfolios of defunct funds is $0.54 \%$ per month, with a $t$-statistic of 2.52. However, the relation for liquidated funds is a little stronger than that for defunct funds. The average alpha difference between the two extreme portfolios of liquidated funds is $0.64 \%$ per month, with a $t$-statistic of 2.58 .

We also examine the relation between MES and fund size to determine whether the low-MES portfolio (i.e., hedge funds with greater systemic risk contribution) can be classified as highly systemic according to the too-big-to-fail criteria. In Acharya et al.'s (2017) application of the MES to financial institutions, the authors argue that large financial institutions often pose systemic risk because if they suffer a substantial capital shortage this might have spillover effects on the entire financial system. Examining Table 5 shows that the same cannot be said for hedge funds. On average, the low-MES portfolio contains the smallest hedge funds while the high-MES portfolio contains the largest hedge funds. This result implies that hedge funds tend to be systemic as part of a herd. Billio et al. (2012) show that small hedge funds are more likely to be affected by systemic risk spillovers. Thus, if a large number of small hedge funds are exposed to similar positions and are funded similarly, then the distress of one small hedge fund could result in the distress of many other small hedge funds.

In summary, the results in Table 5 provide evidence of a positive and statistically significant relation between the systemic risk contribution of hedge funds measured by the MES and hedge fund returns. Furthermore, this relation holds even after taking into account differences in fund characteristics between live and defunct funds.

\subsection{Regression-based analysis}

[Insert Table 6 here]

Table 6 reports the coefficients from the panel regressions of one-month-ahead fund excess returns on the systemic risk contribution of a hedge fund measured by the MES, with 
and without control variables (age, asset size, management fee, incentive fee, redemption notice period, minimum initial investment amount, lockup dummy, and leverage dummy) over the sample period January 1999 to December 2012. The corresponding $t$-statistics clustered by fund and month are reported in the parenthesis.

Consistent with the results from the portfolio-based analysis in Section 5.2, the result from the regression without control variables (the first column of Table 6) shows that hedge fund returns have a positive and statistically significant relation to the systemic risk contribution of a hedge fund measured by the MES. In particular, the coefficient of the MES is -8.03 , with a $t$-statistic of -3.80 . Given a difference in the average MES of $-16.93 \%$ between the low- and high-MES portfolios (reported in the first row of Table 5), the coefficient of the MES (-8.03) translates into a monthly return difference of almost $1.36 \%$ per month, implying an economically significant return spread between average funds in the low- and high-MES portfolios. The result from the regression with the control variables (the second column of Table 6) reports that the systemic risk contribution of a hedge fund still has statistically significant predictive power to explain future hedge fund returns, even after controlling for individual fund characteristics. The coefficient of the MES is -8.05 , with a $t$-statistic of -3.85 .

Because the cross-sectional relation between systemic risk and hedge fund returns can be caused by certain styles with low MES having exceptional returns over the sample period, we also run the one-month-ahead predictive regressions with controlling for style. The third and fourth columns of Table 6 report the coefficients from the panel regressions of one-month-ahead fund excess returns on the systemic risk contribution of a hedge fund measured by the MES with style fixed effect. The results from the regression with controlling for style show that the cross-sectional relation between systemic risk and hedge fund returns is robust to consideration of style. The coefficient of the MES without or with controlling for individual fund characteristics are -8.12 (with a $t$-statistic of -3.86) and -8.25 (with a $t$-statistic of -3.93 ), respectively.

One particular feature of hedge fund returns is their strong autocorrelation. Asness, Krail, and Liew (2001) find that hedge fund indexes exhibit serial correlation and that their returns are correlated to past returns of market factors such as the Standard \& Poor's 500. Getmansky, Lo, and Makarov (2004) present that return smoothing and illiquidity causes hedge fund returns to be positively autocorrelated. Asness, Krail, and 
Liew (2008) provide empirical evidence about the hedge funds' performance smoothing. More recently, Brown et al. (2012) find strong evidence of an MA(2) process in individual fund-of-fund returns. To investigate whether the cross-sectional relation between systemic risk and hedge fund returns is driven by autocorrelation in hedge fund returns, we run the one-month-ahead predictive regressions using unsmoothed returns. ${ }^{20}$

The coefficients from the one-month-ahead predictive regressions using unsmoothed returns are reported from the fifth to eighth column of Table 6. The results from the regression using unsmoothed returns show that the cross-sectional relation between systemic risk and hedge fund returns is not driven by autocorrelation in hedge fund returns. The coefficient of the MES without or with controlling for individual fund characteristics are -6.85 (with a $t$-statistic of -3.27) and -6.87 (with a $t$-statistic of -3.30 ), respectively. Moreover, for unsmoothed return, the cross-sectional relation between systemic risk and hedge fund returns is robust to consideration of style. The coefficient of the MES without or with controlling for individual fund characteristics (with style fixed effect) are -6.89 (with a $t$-statistic of -3.35) and -6.98 (with a $t$-statistic of -3.41), respectively.

One important point in Table 6 is that the coefficient on the incentive fee variable is positive and significant. The coefficient on the incentive fee variable is in the range of 0.008 and 0.014 , with the $t$-statistics ranging from 2.11 to 5.24 . Consistent with earlier studies of hedge funds (see, e.g., Brown, Goetzmann, \& Ibbotson, 1999; Edwards \& Caglayan, 2001; Liang, 1999), this suggests that incentive fee has a strong positive explanatory power for future hedge fund returns (i.e., funds that charge higher incentive fees also earn higher future returns). However, the significance of incentive fee does not change the predictive power of systemic risk on future hedge fund returns.

Another notable observation in Table 6 is that the redemption notice period, the minimum initial investment amount, and the dummy variable for lockup provisions also have positive and significant (or marginally significant) coefficients. This suggests that funds that use lockup and other share restrictions, which enable themselves to invest in illiquid assets, generate higher returns in following months, a finding similar to Aragon (2007). As in incentive fee results, however, even the significance of these variables does not alter or reduce the predictive power of systemic risk over hedge fund returns.

\footnotetext{
${ }^{20}$ To obtain unsmoothed hedge fund returns, we use Getmansky, Lo, and Makarov's (2004) approach with two lags.
} 
In summary, the results from the regression-based analysis are consistent with those from the portfolio-based analysis. The cross-sectional relation between the systemic risk contribution of a hedge fund measured by the MES and hedge fund returns is statistically and economically significant after controlling for individual fund characteristics, hedge fund style, and autocorrelation in hedge fund returns.

\section{Additional tests}

The previous sections present the main result of the paper about the relation between the systemic risk contribution of hedge funds and a cross section of hedge fund returns. This section provides additional analysis, including robustness tests, to highlight the significance of the results.

\subsection{Choice of the systemic event threshold}

To estimate MES, we have to choose the systemic event threshold parameter $C$ for defining systemic events. In Section 5, we estimate MES under the threshold $C$ equal to $-10 \%$, which corresponds approximately to the $5 \%$ quantile of the empirical unconditional market return distribution over the sample period. In this section, we investigate how sensitive the main results obtained in Section 5 are to changing the threshold parameter $C$. To check the effect of the choice of the systemic event threshold parameter $C$ in the MES estimation on our main results, we repeat the portfolio-based analysis based on univariate sorting in Section 5.2 across different threshold parameters.

\section{[Insert Table 7 here]}

Table 7 reports the cross-sectional relation between the MES and expected hedge fund returns across different threshold parameters $(-0.05,-0.08,-0.10$, and -0.15$)$. As expected from Eq. (7), Table 7 shows that the more extreme the threshold of the systemic event, the lower the MES. The results in Table 7 show that our main results remain significant across all threshold parameters. More specifically, the positive relation between systemic risk and hedge fund return does not vary significantly with the choice of the systemic event threshold parameter $C$. From deciles 1 to 10, the expected returns decrease almost 
monotonically across all threshold parameters. Moreover, the average alpha differences between deciles 1 and 10 are all positive and statistically significant (in the range of 0.57 and 0.64 , with the $t$-statistics ranging from 2.51 to 2.92 ), regardless of the choice of the threshold parameter $C$.

\subsection{Controlling for systematic risk}

Since MES is a measure of tail dependence with the market, it is comparable to a downside beta. Although MES and downside beta are similar, they measure different aspects of tail dependence with the market. Specifically, MES focuses on the actual returns of the hedge fund conditional on the market doing poorly while downside beta focuses on the correlation of hedge fund returns with market returns and not on the actual returns themselves. MES also conditions on more severe market outcomes while downside beta conditions on outcomes where the market return is below the mean or median.

\section{[Insert Table 8 here]}

To ensure that the results in Section 5 are not driven by systematic risk, we control for beta by estimating it using the capital asset pricing model (CAPM). We begin by examining the correlation between MES and the CAPM beta. Table 8 reports the average rolling period correlation coefficients between the MES, expected shortfall (ES), volatility, and beta of individual hedge funds from January 1999 to December 2012. Panels A and B report the average Pearson and Spearman rank correlation coefficients, respectively. For each updating period in which the ex ante MES is calculated, we first calculate the ES, volatility and CAPM beta for each individual hedge fund and then compute the Pearson and Spearman rank correlation coefficients between the four variables. This process is repeated on a monthly basis and the correlation coefficients are then averaged across the entire sample period. As expected, both panels show that MES has a significantly negative correlation with beta. Since beta can be interpreted as the correlated volatility of an individual hedge fund relative to that of the market, this result shows that hedge funds with greater systemic risk contributions tend to have greater (correlated) volatility than the market. In the following analysis, we show that all of the results in Section 5 hold after controlling for beta. 
To begin, we examine the predictive ability of the ex ante MES studied in Table 3 when controlling for beta and hedge fund volatility. Table 9 presents the coefficients from the regression of the realized crisis return/covariance on the ex ante MES of individual hedge funds with beta and hedge fund volatility included as control variables. With the exception of the return during the U.S. subprime crisis (first column), the coefficient on MES is significant for all other columns which indicates that the ex ante MES is still able to predict the out-of-sample cross section of systemic risk realizations even after controlling for beta and hedge fund volatility. Consistent with our expectations, the coefficient on beta is significantly negative (positive) for the realized returns (covariances) in both crisis periods. This result implies that hedge funds which are more volatile than the market (i.e., hedge funds with a high beta) tend to have low returns and high covariances with the market during crisis periods.

[Insert Table 10 here]

Next, we revisit the portfolio-based analysis in Section 5.2 and create univariate decile portfolios of hedge funds sorted by beta instead of MES. The motivation behind this is that since MES and beta are negatively correlated, low MES could be a proxy for high beta which means that the results in Table 5 could be driven by systematic risk. Table 10 reports the cross-sectional relation between beta and expected hedge fund returns. Decile 1 is the portfolio of hedge funds with the highest beta and decile 10 is the portfolio of hedge funds with the lowest beta. If the results in Table 5 are driven by systematic risk, then expected risk-adjusted returns should decrease from deciles 1 to 10 in Table 10 . However, Table 10 shows that there is no visible relation between beta and hedge fund returns when portfolios are sorted into deciles based on beta. For example, in Panel A, although alpha initially decreases when moving from decile 1 to decile 2 , it increases when moving from decile 2 to decile 3 . Thus, the results in Table 5 are unlikely to be driven by the systematic risk of hedge funds. Finally, we redo the regression-based analysis in Section 5.3 but control for beta in the regressions. Table 11 presents the results. The coefficient on beta is statistically insignificant across all columns which confirms that the positive relation between systemic risk and hedge fund returns is not driven by beta. 
[Insert Table 11 here]

\subsection{Long-term predictability}

Because hedge fund investors are often confronted with share restrictions, such as a lockup provision or a redemption notice period, they cannot immediately withdraw or rebalance their shares. It is therefore of interest to examine how far ahead an MES can predict the cross section of hedge fund returns. To check the long-term predictive power of the MES, we calculate portfolio returns using not only one-month-ahead returns but also one-quarter-ahead, two-quarter-ahead, three-quarter-ahead, and one-year-ahead returns. For example, in the case of the MES measured from January 1994 to December 1998, we assign one-month-ahead (i.e., January 1999), one-quarter-ahead (i.e., April 1999), two-quarter-ahead (i.e., July 1999), three-quarter-ahead (i.e., October 1999), and one-year-ahead (i.e., January 2000) returns to the estimated MES.

[Insert Table 12 here]

Table 12 reports the cross-sectional relation between the MES and expected hedge fund returns across different assigned returns. Although the results in Table 12 show that the predictive power of the MES declines as we use lagged data to calculate the measure, the positive relation between systemic risk and hedge fund return still holds. From deciles 1 to 10, the expected returns decrease almost monotonically, except for the one-year-ahead return case. Moreover, the average alpha differences between deciles 1 and 10 are positive and statistically significant at the conventional level, with the exception of the one-year-ahead return case, which exhibits an insignificant but still positive average alpha difference. These results suggest that MES is a useful tool for evaluating the systemic risk contribution of hedge funds in practice, even after considering share restrictions.

\subsection{Long-run performance}

As discussed in Section 5.3, hedge fund returns frequently exhibit a strong degree of autocorrelation. This correlation can be the result of the infrequent trading of illiquid securities in their portfolios or of managerial manipulation to smooth returns. The serial correlation of hedge fund returns suggests that measuring a fund's performance over a 
long period can be more indicative of its performance. To investigate this effect, we use multiple-month cumulative returns computed for non-overlapping intervals. For example, to calculate a three-month holding period return, portfolios are updated only at the beginning of January, April, July, and October of each year.

[Insert Table 13 here]

Table 13 reports the cross-sectional relation between the MES and expected hedge fund returns across different holding periods (one, three, six, and 12 months). The returns in Table 13 are annualized to facilitate easy comparisons across different holding periods. The results in Table 13 indicate that the positive relation between systemic risk and hedge fund return does not vary significantly with the holding period or rebalancing frequency. From deciles 1 to 10, the expected returns decrease almost monotonically. Moreover, the average return difference between deciles 1 and 10 varies by $10.96-12.23 \%$ per annum ( $t$-statistics above 1.99). From a practical point of view, the long-run performance of the low-minus-high MES portfolio also relaxes some concerns about monthly portfolio rebalancing, which would require redemptions subject to notice periods and lockups.

[Insert Fig. 2 here]

Since the profitability of a strategy over longer holding periods can vary with a particular starting month, we calculate the long-run performance of the low-minus-high MES portfolio re-formed at the beginning of each month. Each panel in Fig. 2 presents the time series of the returns of the low-minus-high MES portfolio formed at the beginning of each month, but the returns are cumulated over the following few months without rebalancing. For example, Panel C of Fig. 2 plots the six-month cumulative return for the low-minus-high MES portfolio while keeping the funds fixed for six months and the portfolio is re-formed each month. Panels $\mathrm{B}$ and $\mathrm{C}$ in Fig. 2 suggest that no matter when the portfolio is formed during the sample period, as long as it is not rebalanced for three or six months, it is likely to earn positive profits most of the time, which supports the results in Table 13. 


\subsection{Crisis versus non-crisis periods}

Section 5.1 suggests that systemically risky hedge funds suffer large losses when systemic event occurs. Moreover, Section 5.2 and Section 5.3 show that the relation between systemic risk and expected hedge fund returns is positive and statistically significant. Combining these results on the relation between systemic risk and hedge fund returns, we expect that because funds exposed to systemic risk suffer a shortfall in the event of a crisis period (i.e., ex post), they earn a premium prior to the crisis period (i.e., ex ante). To confirm our conjecture, this section compares the performance of the low-minus-high MES portfolio during crisis and non-crisis periods.

[Insert Table 14 here]

The sample period includes two significant crises: September to November of 2008 (the U.S. subprime crisis), and July to September of 2011 (the European sovereign debt crisis). Panel A of Table 14 reports the average monthly returns of portfolios that are rebalanced monthly. Panel B reports the three-month cumulative returns of portfolios that are rebalanced quarterly. For the crisis periods, the portfolios are rebalanced at the beginning of each crisis and are held for the three-month crisis period. For the non-crisis periods, portfolios are rebalanced at the beginning of each calendar quarter and only quarters that do not overlap with any of the crisis periods are used. For the entire sample period, all calendar quarters are used.

The results in Table 14 confirm our conjecture, showing that the low-minus-high MES portfolios earn negative returns during crisis periods, while positive returns are observed during non-crisis periods. Moreover, the average negative returns during crisis periods are higher (in absolute value) than those during non-crisis periods. In particular, for the monthly returns of portfolios, the average return of the low-minus-high MES portfolios during crisis periods is $-7.89 \%$ (with a $t$-statistic of -8.34 ), while that during non-crisis periods is $1.19 \%$ (with a $t$-statistic of 3.02). Moreover, for the three-month cumulative returns of portfolios, the average return of the low-minus-high MES portfolios during crisis periods is $-19.84 \%$ (with a $t$-statistic of -60.95), while that during non-crisis periods is $3.58 \%$ (with a $t$-statistic of 2.81 ). These results imply that the positive relation between the systemic risk contribution of hedge funds measured by the MES and hedge fund 
returns is due to compensation for the realized losses during systemic events, which can be interpreted as large tail risk during systemic events.

\section{Conclusion}

This paper examines the cross-sectional relation between systemic risk and hedge fund returns. The systemic risk of individual hedge funds is measured using the MES proposed by Acharya et al. (2017) and Brownlees and Engle (2017). This paper's main research question is whether the systemic risk contribution of hedge funds explains the crosssectional variation in hedge fund returns. To answer this question, we conduct analyses adopted from an asset pricing framework, at both the portfolio level (portfolio-based analysis) and the individual level (regression-based analysis).

Our paper's major findings can be summarized as follows. First, we find that ex ante MES can predict the cross section of systemic risk contribution of individual hedge funds during crisis periods. Second, we find evidence for a positive and statistically significant relation between the systemic risk contribution of hedge funds measured by the MES and hedge fund returns. Moving from a low- to a high-MES portfolio, expected portfolio returns decrease almost monotonically. The risk-adjusted return of a hedge fund portfolio with high systemic risk is $0.64 \%$ per month higher than for low systemic risk during 1994-2012, while negative performance is observed during crisis periods. The relation between systemic risk and hedge fund returns holds for both live and defunct funds. Third, the relation between systemic risk and hedge fund returns holds even after controlling for individual fund characteristics, hedge fund style, and autocorrelation in hedge fund returns. Therefore, these major findings reveal that systemic risk is a powerful determinant of cross-sectional variations in hedge fund returns. These results also imply that the positive relation between the systemic risk contribution of hedge funds and hedge fund returns is due to compensation for the realized losses during systemic events. Moreover, since MES can also be interpreted as tail risk, these results imply that investors are willing to demand a premium to carry tail risk during systemic events.

Our findings provide some insights into the financial regulation and risk management of hedge funds and imply that hedge fund managers have an incentive to take systemic risks unless the external costs thereof are internalized by each hedge fund. Whereas 
current financial regulations and risk management are designed to limit each entity's risk seen in isolation, this paper supports the attitude that they should be focused on limiting systemic risk, which is the risk of a financial crisis and its spillover to the economy at large. 


\section{Appendix A Specification of volatility, correlation, and tail expectations}

To estimate the marginal expected shortfall (MES), we use the specifications of volatility, correlation, and tail expectations of Brownlees and Engle (2017). In this appendix, we briefly introduce the specification choices in the estimation of the MES.

\section{A.1 Volatility}

Given the large variety of GARCH specification, we choose a TARCH specification to model volatility (Glosten, Jagananthan, \& Runkle, 1993; Rabemananjara \& Zakoïan, 1993). The conditional variance in this specification class is modeled by

$$
\begin{aligned}
& \sigma_{m, t}^{2}=\omega_{m}+\alpha_{m} r_{m, t-1}^{2}+\alpha_{m}^{-} r_{m, t-1}^{2} I_{m, t-1}^{-}+\beta_{m} \sigma_{m, t-1}^{2}, \\
& \sigma_{i, t}^{2}=\omega_{i}+\alpha_{i} r_{i, t-1}^{2}+\alpha_{i}^{-} r_{i, t-1}^{2} I_{i, t-1}^{-}+\beta_{i} \sigma_{i, t-1}^{2},
\end{aligned}
$$

where $I_{i, t}^{-}=1$ if $\left\{r_{i, t}<0\right\}$ and $I_{m, t}^{-}=1$ if $\left\{r_{m, t}<0\right\}$. The stationary condition of the volatility dynamics is $\left(\alpha+\alpha^{-} / 2+\beta\right)<1$ under the assumption that the probability of a negative shock is $1 / 2$. This model has the advantage of capturing the leverage effect, which is the tendency of volatility to increase more with negative news than with positive news.

\section{A.2 Correlation}

We use the DCC approach Engle $(2002,2009)$ to model time-varying correlation. Let $R_{i, t}$ be the time-varying correlation matrix of the market and hedge fund $i$ 's return. Then the covariance matrix of the market and hedge fund return can be decomposed as

$$
\begin{aligned}
\operatorname{Var}_{t-1}\left(\begin{array}{c}
r_{i, t} \\
r_{m, t}
\end{array}\right) & =D_{i, t} R_{i, t} D_{i, t} \\
& =\left[\begin{array}{cc}
\sigma_{i, t} & 0 \\
0 & \sigma_{m, t}
\end{array}\right]\left[\begin{array}{cc}
1 & \rho_{i, t} \\
\rho_{i, t} & 1
\end{array}\right]\left[\begin{array}{cc}
\sigma_{i, t} & 0 \\
0 & \sigma_{m, t}
\end{array}\right] .
\end{aligned}
$$

Rather than directly modeling the $R_{i, t}$ matrix, the DCC framework models the pseudo- 
correlation matrix $Q_{i, t}$, a positive definite matrix defined as

$$
R_{i, t}=\operatorname{diag}\left(Q_{i, t}\right)^{-1 / 2} Q_{i, t} \operatorname{diag}\left(Q_{i, t}\right)^{-1 / 2}
$$

where the $\operatorname{diag}(A)$ matrix operator denotes a matrix with the same elements of the $A$ matrix on the diagonal and zero otherwise. Then, the evolution of the correlation in the standard DCC model is given by

$$
Q_{i, t}=(1-a-b) \bar{Q}_{i}+a u_{i, t-1} u_{i, t-1}^{\prime}+b Q_{i, t-1}
$$

where $u_{i, t}=Q_{i, t-1}^{*} \varepsilon_{i, t}$, with $Q_{i, t}^{*}=\operatorname{diag}\left(Q_{i, t}\right)^{1 / 2}$ and $\bar{Q}_{i}=\mathbb{E}\left[u_{i, t} u_{i, t}^{\prime}\right]$, and $a$ and $b$ are scalars such that $a+b<1$. As long as $Q_{i, t}$ is positive definite, $Q_{i, t}^{*}$ guarantees that $R_{i, t}$ is a correlation matrix with ones on the diagonal and absolute values of all the other elements less than one.

\section{A.3 Tail expectations}

To calculate MES in Eq. (7), we have to estimate the tail expectations $\mathbb{E}\left(\varepsilon_{m, t} \mid \varepsilon_{m, t}<\kappa\right)$ and $\mathbb{E}\left(\xi_{i, t} \mid \varepsilon_{m, t}<\kappa\right)$. Given the value of the variance $\left(\sigma_{m, t}^{2}, \sigma_{i, t}^{2}\right)$ and conditional correlation $\rho_{t}$, these expectations can be estimated by simply averaging the two residuals in all cases that satisfy the condition $\varepsilon_{m, t}<\kappa$. However, when $-\kappa$ is large, this estimator will be unstable, since there are only a small number of observations. For this reason, we use a nonparametric kernel estimation approach to improve the efficiency of these simple estimators. Let

$$
K_{h}(t)=\int_{\infty}^{t / h} k(u) d u
$$

where $k(u)$ is a kernel function and $h$ is a positive bandwidth. Then

$$
\widehat{\mathbb{E}}_{h}\left(\varepsilon_{m, t} \mid \varepsilon_{m, t}<\kappa\right)=\frac{1}{n \widehat{p}_{h}} \sum_{i=1}^{n} \varepsilon_{m, t} K_{h}\left(\varepsilon_{m, t}-\kappa\right),
$$


and

$$
\widehat{\mathbb{E}}_{h}\left(\xi_{i, t} \mid \varepsilon_{m, t}<\kappa\right)=\frac{1}{n \widehat{p}_{h}} \sum_{i=1}^{n} \xi_{i, t} K_{h}\left(\varepsilon_{m, t}-\kappa\right),
$$

where

$$
\widehat{p}_{h}=\frac{1}{n} \sum_{i=1}^{n} K_{h}\left(\varepsilon_{m, t}-\kappa\right) .
$$




\section{References}

Acharya, V., Pedersen, L., Philippon, T., \& Richardson, M. (2017). "Measuring systemic risk". Review of Financial Studies, 30(1), 2-47.

Ackermann, C., McEnally, R., \& Ravenscraft, D. (1999). "The performance of hedge funds: risk, return and incentives". Journal of Finance, 54, 833-874.

Adrian, T., \& Brunnermeier, M. (2016). "CoVaR". American Economic Review, 106(7), $1705-1741$.

Agarwal, V., Daniel, N., \& Naik, N. (2009). "Role of managerial incentives and discretion in hedge fund performance". Journal of Finance, 64, 2221-2256.

Agarwal, V., \& Naik, N. (2004). "Risks and portfolio decisions involving hedge funds". Review of Financial Studies, 17, 63-98.

Aggarwal, R., \& Jorion, P. (2010). "The performance of emerging hedge funds and managers". Journal of Financial Economics, 96, 238-256.

Allen, L., Bali, T. G., \& Tang, Y. (2012). "Does systemic risk in the financial sector predict future economic downturns?". Review of Financial Studies, 25(10), 3000-3036.

Andrews, D. W. K., \& Monahan, J. C. (1992). "An improved heteroskedasticity and autocorrelation consistent covariance matrix estimator". Econometrica, 60(4), 953-966.

Aragon, G. (2007). "Share restrictions and asset pricing: evidence from the hedge fund industry". Journal of Financial Economics, 83, 33-58.

Asness, C., Krail, R., \& Liew, J. (2001). "Do hedge funds hedge?". Journal of Portfolio Management, 20, 6-19.

Asness, C., Krail, R., \& Liew, J. (2008). "Conditional return smoothing in the hedge fund industry". Journal of Financial and Quantitative Analysis, 43, 267-298.

Bali, T., Brown, S., \& Caglayan, M. (2011). "Do hedge funds' exposures to risk factors predict their future returns?". Journal of Financial Economics, 101, 36-68.

Bali, T., Brown, S., \& Caglayan, M. (2012). "Systematic risk and the cross section of hedge fund returns". Journal of Financial Economics, 106, 114-131.

Bali, T., Gokcan, S., \& Liang, B. (2007). "Value at risk and the cross-section of hedge fund returns". Journal of Banking and Finance, 31, 1135-1166.

Bessler, W., \& Kurmann, P. (2013). Funds of Hedge Funds, Efficient Portfolios, and Investor Clienteles: Empirical Evidence from Growth and Financial Crisis Periods. In: Gregoriou, G. (Eds.), Reconsidering Funds of Hedge Funds. Elsevier, pp. 451477.

Billio, M., Getmansky, M., Lo, A., \& Pelizzon, L. (2012). "Econometric measures of connectedness and systemic risk in the finance and insurance sectors". Journal of Financial Economics, 104, 535-559.

Boyson, N. (2008). "Hedge fund performance persistence: a new approach". Financial 
Analysts Journal, 64, 27-44.

Boyson, N., Stahel, C., \& Stulz, R. (2010). "Hedge fund contagion and liquidity shocks". Journal of Finance, 65, 1789-1816.

Brown, S., \& Goetzmann, W. (2003). "Hedge funds with style". Journal of Portfolio Management, 29, 101-112.

Brown, S., Goetzmann, W., \& Ibbotson, R. (1999). "Offshore hedge funds: survival and performance 1989-95". Journal of Business, 72, 91-117.

Brown, S., Goetzmann, W., Ibbotson, R., \& Ross, S. (1992). "Survivorship bias in performance studies". Review of Financial Studies, 5, 553-580.

Brown, S., Goetzmann, W., \& Park, J. (2001). "Careers and survival: competition and risk in the hedge fund and CTA industry". Journal of Finance, 56, 1869-1886.

Brown, S., Gregoriou, G., \& Pascalau, R. (2012). "Is it possible to overdiversify? The case of funds of hedge funds". Review of Asset Pricing Studies, 2, 89-110.

Brownlees, C., \& Engle, R. (2017). "SRISK: a conditional capital shortfall measure of systemic risk". Review of Financial Studies, 30(1), 48-79.

Brunnermeier, M., \& Pedersen, L. (2009). "Market liquidity and funding liquidity". Review of Financial Studies, 22, 2201-2238.

Buraschi, A., Kosowski, R., \& Trojani, F. (2014). "When there is no place to hide: correlation risk and the cross-section of hedge fund returns". Review of Financial Studies, 27, 581-616.

Chan, N., Getmansky, M., Haas, S., \& Lo, A. (2006). Systemic Risk and Hedge Funds. In: Carey, M., Stulz, R. (Eds.), The Risks of Financial Institutions. University of Chicago Press, pp. 235-330.

Edwards, F., \& Caglayan, M. (2001). "Hedge fund performance and manager skill". Journal of Futures Markets, 21, 1003-1028.

Engle, R. (2002). "Dynamic conditional correlation: a simple class of multivariate generalized autoregressive conditional heteroskedasticity models". Journal of Business and Economic Statistics, 20, 339-350.

Engle, R. (2009). Anticipating Correlations: A New Paradigm for Risk Management. Princeton University Press.

Fama, E., \& French, K. (1992). "The cross-section of expected stock returns". Journal of Finance, 47, 427-465.

Fama, E., \& MacBeth, J. (1973). "Risk, return and equilibrium: empirical tests". Journal of Political Economy, 81, 607-636.

Fung, W., \& Hsieh, D. (1997). "Empirical characteristics of dynamic trading strategies: the case of hedge funds". Review of Financial Studies, 10, 275-302.

Fung, W., \& Hsieh, D. (2000). "Performance characteristics of hedge funds and commodity funds: natural versus spurious biases". Journal of Financial and Quantitative Analysis, 35, 291-307. 
Fung, W., \& Hsieh, D. (2001). "The risk in hedge fund strategies: theory and evidence from trend followers". Review of Financial Studies, 14, 313-341.

Fung, W., \& Hsieh, D. (2002). "Asset-based style factors for hedge funds". Financial Analysts Journal, 58, 16-27.

Fung, W., \& Hsieh, D. (2004). "Hedge fund benchmarks: a risk-based approach". Financial Analysts Journal, 60, 65-80.

Fung, W., \& Hsieh, D. (2009). "Measurement biases in hedge fund performance data: an update". Financial Analysts Journal, 65, 1-3.

Fung, W., Hsieh, D., Naik, N., \& Ramadorai, T. (2008). "Hedge funds: performance, risk, and capital formation". Journal of Finance, 63, 1777-1803.

Getmansky, M., Lo, A., \& Makarov, I. (2004). "An econometric model of serial correlation and illiquidity in hedge funds returns". Journal of Financial Economics, 74, 529610.

Getmansky, M., Lo, A., \& Mei, S. (2004). "Sifting through the wreckage: lessons from recent hedge-fund liquidations". Journal of Investment Management, 2, 6-38.

Glosten, L., Jagananthan, R., \& Runkle, D. (1993). "On the relation between the expected value and the volatility of the nominal excess return on stocks". Journal of Finance, 48, 1779-1801.

Goetzmann, W., Ingersoll, J., \& Ross, S. (2003). "High-water marks and hedge fund management contracts". Journal of Finance, 58, 1685-1717.

Hildebrand, P. (2007). "Hedge funds and prime broker-dealers: steps towards a best practice proposal". Financial Stability Review, 10, 67-76.

Joenväärä, J. (2009). "On hedge funds' relation to systemic risk". Working paper. University of Oulu.

Kambhu, J., Schuermann, T., \& Stiroh, K. (2007). "Hedge funds, financial intermediation, and systemic risk". Economic Policy Review, 13, 1-18.

Kaufman, G. (2000). "Banking and currency crises and systemic risk: a taxonomy and review". Financial Markets, Institutions and Instruments, 9, 69-131.

King, M., \& Maier, P. (2009). "Hedge funds and financial stability: regulating prime brokers will mitigate systemic risks". Journal of Financial Stability, 5, 283-297.

Klaus, B., \& Rzepkowski, B. (2009). "Hedge funds and prime brokers: the role of funding risk". Working paper. Goethe University.

Kosowski, R., Naik, N., \& Teo, M. (2007). "Do hedge funds deliver alpha? A Bayesian and bootstrap analysis". Journal of Financial Economics, 84, 229-264.

Liang, B. (1999). "On the performance of hedge funds". Financial Analysts Journal, 55, $72-85$.

Liang, B. (2000). "Hedge funds: the living and the dead". Journal of Financial and Quantitative Analysis, 35, 309-326.

Liang, B., \& Park, H. (2007). "Risk measures for hedge funds: a cross-sectional approach". 
European Financial Management, 13, 333-370.

Lo, A. (2001). "Risk management for hedge funds: introduction and overview". Financial Analysts Journal, 57, 16-33.

McCarthy, C. (2006). "Hedge funds: what should be the regulatory response?". SUERF European Money and Finance Forum.

Mitchell, M., \& Pulvino, T. (2001). "Characteristics of risk in risk arbitrage". Journal of Finance, 56, 2135-2175.

Petersen, M. (2009). "Estimating standard errors in finance panel data sets: comparing approaches". Review of Financial Studies, 22, 435-480.

Rabemananjara, R., \& Zakoïan, J. (1993). "Threshold ARCH models and asymmetries in volatility". Journal of Applied Econometrics, 9, 31-49.

Sadka, R. (2010). "Liquidity risk and the cross-section of hedge fund returns". Journal of Financial Economics, 98, 54-71.

Titman, S., \& Tiu, C. (2011). "Do the best hedge funds hedge?". Review of Financial Studies, 24, 123-168. 


\section{Tables}

\section{Table 1}

Descriptive statistics for hedge fund returns.

Panel A: Summary statistics year by year (1994-2012)

\begin{tabular}{|c|c|c|c|c|c|c|c|c|c|c|c|}
\hline \multirow[b]{2}{*}{ Year } & \multirow[b]{2}{*}{$\begin{array}{l}\text { Year- } \\
\text { start }\end{array}$} & \multirow[b]{2}{*}{ Entries } & \multirow[b]{2}{*}{ Dissolved } & \multirow[b]{2}{*}{$\begin{array}{l}\text { Year- } \\
\text { end }\end{array}$} & \multirow{2}{*}{\multicolumn{2}{|c|}{$\begin{array}{c}\text { Total AUM } \\
\text { (billion } \$ \text { ) }\end{array}$}} & \multicolumn{5}{|c|}{ EWHF Portfolio Monthly Returns (\%) } \\
\hline & & & & & & & Mean & Median & $\begin{array}{l}\text { Std. } \\
\text { Dev. }\end{array}$ & Minimum & Maximum \\
\hline 1994 & 514 & 182 & 0 & 696 & 33.63 & & -0.06 & 0.17 & 1.15 & -1.72 & 1.68 \\
\hline 1995 & 696 & 213 & 0 & 909 & 45.78 & & 1.36 & 1.45 & 1.04 & -0.86 & 2.64 \\
\hline 1996 & 909 & 249 & 22 & 1136 & 63.42 & & 1.48 & 1.89 & 1.39 & -1.79 & 3.41 \\
\hline 1997 & 1136 & 266 & 36 & 1366 & 99.44 & & 1.38 & 1.28 & 1.91 & -1.53 & 4.38 \\
\hline 1998 & 1366 & 281 & 48 & 1599 & 106.1 & & 0.16 & 0.03 & 2.77 & -7.05 & 3.38 \\
\hline 1999 & 1599 & 328 & 75 & 1852 & 126.0 & & 2.20 & 1.71 & 2.21 & -0.64 & 6.57 \\
\hline 2000 & 1852 & 327 & 91 & 2088 & 139.4 & & 0.71 & 0.51 & 2.36 & -2.29 & 5.70 \\
\hline 2001 & 2088 & 425 & 138 & 2375 & 179.9 & & 0.53 & 0.88 & 1.34 & -2.16 & 2.63 \\
\hline 2002 & 2375 & 453 & 90 & 2738 & 198.8 & & 0.18 & 0.44 & 1.10 & -1.97 & 1.76 \\
\hline 2003 & 2738 & 485 & 166 & 3057 & 291.9 & & 1.38 & 1.28 & 0.90 & 0.07 & 3.27 \\
\hline 2004 & 3057 & 496 & 129 & 3424 & 411.3 & & 0.71 & 0.72 & 1.16 & -1.05 & 2.80 \\
\hline 2005 & 3424 & 498 & 204 & 3718 & 466.1 & & 0.74 & 1.25 & 1.35 & -1.50 & 2.07 \\
\hline 2006 & 3718 & 325 & 330 & 3713 & 547.0 & & 1.03 & 1.36 & 1.38 & -1.59 & 3.43 \\
\hline 2007 & 3713 & 294 & 375 & 3632 & 663.1 & & 0.94 & 1.02 & 1.42 & -1.70 & 2.93 \\
\hline 2008 & 3632 & 241 & 531 & 3342 & 449.4 & & -1.78 & -1.89 & 2.77 & -6.86 & 1.74 \\
\hline 2009 & 3342 & 170 & 649 & 2863 & 402.8 & & 1.62 & 1.46 & 1.65 & -0.96 & 5.07 \\
\hline 2010 & 2863 & 24 & 329 & 2558 & 369.3 & & 0.78 & 0.95 & 1.77 & -3.05 & 3.15 \\
\hline 2011 & 2558 & 0 & 434 & 2124 & 327.6 & & -0.44 & -0.24 & 1.83 & -3.88 & 2.46 \\
\hline 2012 & 2124 & 0 & 325 & 1799 & 258.7 & & 0.61 & 0.68 & 1.38 & -2.60 & 2.80 \\
\hline \multicolumn{12}{|c|}{ Panel B: Cross-sectional statistics (1994-2012) } \\
\hline & & & & & & $\mathrm{N}$ & Mean & Median & $\begin{array}{l}\text { Std. } \\
\text { Dev. }\end{array}$ & Minimum & Maximum \\
\hline \multirow{5}{*}{\multicolumn{6}{|c|}{$\begin{array}{l}\text { Average monthly return over the life of the fund (\%) } \\
\text { Average monthly AUM over the life of the fund (million } \$ \text { ) } \\
\text { Age of the fund (months in existence) } \\
\text { Management fee }(\%) \\
\text { Incentive fee }(\%)\end{array}$}} & 5771 & 0.53 & 0.50 & 0.73 & -8.76 & 7.64 \\
\hline & & & & & & 5771 & 144.96 & 44.11 & 397.89 & 0.01 & 14423.07 \\
\hline & & & & & & 5771 & 94.55 & 80.00 & 52.43 & 36.00 & 469.00 \\
\hline & & & & & & 5749 & 1.41 & 1.50 & 0.66 & 0.00 & 22.00 \\
\hline & & & & & & 5741 & 15.14 & 20.00 & 7.75 & 0.00 & 50.00 \\
\hline
\end{tabular}

Our sample includes 5,771 funds, of which 1,799 are live and 3,972 defunct, between January 1994 and December 2012. For each year from 1994 to 2012, Panel A reports the number of hedge funds that entered the database, the number of hedge funds dissolved, the total AUM at the end of each year for all hedge funds (in billions of U.S. dollars), and the mean, median, standard deviation, minimum, and maximum monthly percentage returns on an EWHF portfolio. Panel B reports for the period 1994-2012 the cross-sectional mean, median, standard deviation, minimum, and maximum statistics for hedge fund characteristics, including returns, size, age, management fee, and incentive fee. 
Table 2

GARCH-DCC parameter estimates.

\begin{tabular}{lcccccccc}
\hline & \multicolumn{4}{c}{ TARCH } & & \multicolumn{3}{c}{ DCC } \\
\cline { 2 - 4 } \cline { 8 - 9 } & $\omega_{i}$ & $\alpha_{i}$ & $\alpha_{i}^{-}$ & $\beta_{i}$ & & $1-a-b$ & $a$ & $b$ \\
\hline Mean & 0.0005 & 0.1627 & 0.1739 & 0.5031 & & 0.5101 & 0.1225 & 0.3674 \\
Median & 0.0001 & 0.0866 & 0.1216 & 0.5864 & & 0.5380 & 0.0923 & 0.2511 \\
Std. Dev. & 0.0022 & 0.2055 & 0.4003 & 0.3395 & & 0.3686 & 0.1309 & 0.3705 \\
$q_{0.1}$ & 0 & 0 & -0.2870 & 0 & & 0.0425 & 0 & 0 \\
$q_{0.9}$ & 0.0012 & 0.4551 & 0.7800 & 0.9056 & 1 & 0.3056 & 0.8732 \\
\hline
\end{tabular}

This table reports the mean, median, standard deviation, $10 \%$, and $90 \%$ quantiles of the GARCH-DCC parameter estimates based on Eqs. (11) and (14) in Appendix A. The parameter estimates are obtained over the full sample, which spans December 1994 to December 2012 for a total of 228 observations. 


\section{Table 3}

MES predictions for crisis returns and crisis covariance.

\begin{tabular}{|c|c|c|c|c|c|c|}
\hline & \multicolumn{3}{|c|}{ U.S. subprime crisis } & \multicolumn{3}{|c|}{ European sovereign debt crisis } \\
\hline & Return & $\begin{array}{c}3 \text {-month } \\
\text { covariance }\end{array}$ & $\begin{array}{c}1 \text {-year } \\
\text { covariance }\end{array}$ & Return & $\begin{array}{c}3 \text {-month } \\
\text { covariance }\end{array}$ & $\begin{array}{c}\text { 1-year } \\
\text { covariance }\end{array}$ \\
\hline Intercept & $\begin{array}{l}-0.15^{\text {*** }} \\
(-42.59)\end{array}$ & $\begin{array}{c}-0.13 \\
(-0.20)\end{array}$ & $\begin{array}{c}35.20^{* * *} \\
(31.13)\end{array}$ & $\begin{array}{c}-0.02^{* * *} \\
(-8.26)\end{array}$ & $\begin{array}{c}3.84^{* * *} \\
(8.27)\end{array}$ & $\begin{array}{l}4.33^{* * *} \\
(8.18)\end{array}$ \\
\hline$M E S$ & $\begin{array}{l}2.35^{* * *} \\
(11.54)\end{array}$ & $\begin{array}{c}-176.07^{* * *} \\
(-3.85)\end{array}$ & $\begin{array}{c}-883.89^{* * *} \\
(-12.48)\end{array}$ & $\begin{array}{l}1.58^{* * *} \\
(16.85)\end{array}$ & $\begin{array}{c}-169.62^{* * *} \\
(-9.43)\end{array}$ & $\begin{array}{c}-407.46^{* * *} \\
(-20.62)\end{array}$ \\
\hline Adjusted $R^{2}$ & 0.12 & 0.02 & 0.20 & 0.36 & 0.24 & 0.49 \\
\hline
\end{tabular}

This table reports the coefficients from the regression of the realized crisis return/covariance on the ex ante MES for individual hedge funds. Since we do not perform any sign conversion in the estimation of the MES, a significantly negative MES value represents a high systemic risk. For the U.S. subprime crisis, the crisis return and crisis covariance are the realized return and realized covariance for September-November 2008, respectively. The MES is estimated with data as of August 2008. For the European sovereign debt crisis, the crisis return and crisis covariance are the realized return and realized covariance for July-September 2011, respectively. The MES is estimated with data as of June 2011. In the case of the crisis covariance, we also use the realized covariance over one year from the start of each crisis. Newey-West $t$-statistics are reported in the parenthesis. The adjusted $R^{2}$ values are reported in the last row. ${ }^{*},{ }^{* *}$, and ${ }^{* * *}$ indicate significance at the $10 \%, 5 \%$, and $1 \%$ level, respectively. 
Table 4

Predictive ability of aggregate MES for the CFNAI.

\begin{tabular}{|c|c|c|c|c|c|c|c|c|c|c|c|c|}
\hline & \multicolumn{12}{|c|}{$C F N A I_{t+n}$} \\
\hline & $n=1$ & $n=2$ & $n=3$ & $n=4$ & $n=5$ & $n=6$ & $n=7$ & $n=8$ & $n=9$ & $n=10$ & $n=11$ & $n=12$ \\
\hline Intercept & $\begin{array}{c}5.77 \\
(1.19)\end{array}$ & $\begin{array}{l}-0.36 \\
(-0.07)\end{array}$ & $\begin{array}{c}8.38 \\
(1.33)\end{array}$ & $\begin{array}{c}0.03 \\
(0.01)\end{array}$ & $\begin{array}{l}-1.95 \\
(-0.26)\end{array}$ & $\begin{array}{c}-2.64 \\
(-0.33)\end{array}$ & $\begin{array}{l}-2.39 \\
(-0.32)\end{array}$ & & $\begin{array}{l}-9.98 \\
(-1.11)\end{array}$ & & $\begin{array}{c}-5.54 \\
(-0.67)\end{array}$ & $\begin{array}{l}-1.88 \\
(-0.22)\end{array}$ \\
\hline$A M E S$ & $\begin{array}{l}-4.82 \\
(-1.42)\end{array}$ & $\begin{array}{c}-11.16^{* * * *} \\
(-2.65)\end{array}$ & $\begin{array}{c}-13.08^{* * *} \\
(-2.60)\end{array}$ & $\begin{array}{c}-20.06^{* * *} \\
(-3.91)\end{array}$ & $\begin{array}{c}-28.45^{* * *} \\
(-3.66)\end{array}$ & $\begin{array}{c}-31.99^{* * *} \\
(-4.16)\end{array}$ & $\begin{array}{c}-37.07^{* * *} \\
(-4.39)\end{array}$ & $\begin{array}{c}-41.10^{* * * *} \\
(-5.10)\end{array}$ & $\begin{array}{c}-42.38^{* * *} \\
(-5.15)\end{array}$ & $\begin{array}{c}-42.43^{* * *} \\
(-6.98)\end{array}$ & $\begin{array}{c}-37.45^{* * *} \\
(-5.84)\end{array}$ & $\begin{array}{c}-31.11^{* * *} \\
(-4.68)\end{array}$ \\
\hline & {$[0.008]$} & {$[0.041]$} & [0.047] & {$[0.085]$} & {$[0.152]$} & {$[0.181]$} & {$[0.227]$} & {$[0.289]$} & {$[0.349]$} & {$[0.368]$} & {$[0.366]$} & {$[0.369]$} \\
\hline$D E F$ & $\begin{array}{l}-28.67 \\
(-1.58)\end{array}$ & $\begin{array}{l}-13.80 \\
(-0.81)\end{array}$ & $\begin{array}{l}13.78 \\
(0.62)\end{array}$ & $\begin{array}{l}-3.36 \\
(-0.14)\end{array}$ & $\begin{array}{l}-14.84 \\
(-0.57)\end{array}$ & $\begin{array}{l}-1.83 \\
(-0.06)\end{array}$ & $\begin{array}{c}0.40 \\
(0.01)\end{array}$ & $\begin{array}{l}-33.20 \\
(-1.30)\end{array}$ & $\begin{array}{l}-32.76 \\
(-1.22)\end{array}$ & $\begin{array}{l}-46.88 \\
(-1.63)\end{array}$ & $\begin{array}{l}-31.20 \\
(-1.17)\end{array}$ & $\begin{array}{l}-20.68 \\
(-0.65)\end{array}$ \\
\hline & {$[0.014]$} & [0.003] & {$[0.003]$} & {$[0.000]$} & ([0.002] & {$[0.000]$} & {$[0.000]$} & {$[0.012]$} & [0.013] & {$[0.025]$} & {$[0.012]$} & [0.005] \\
\hline$T E R M$ & $\begin{array}{l}6.08^{*} \\
(1.70) \\
{[0.010]}\end{array}$ & $\begin{array}{c}4.40 \\
(0.99) \\
{[0.005]}\end{array}$ & $\begin{array}{c}5.97 \\
(1.15) \\
{[0.008]}\end{array}$ & $\begin{array}{c}5.86 \\
(0.87) \\
{[0.006]}\end{array}$ & $\begin{array}{l}10.30 \\
(1.58) \\
{[0.018]}\end{array}$ & $\begin{array}{c}14.32^{* * *} \\
(2.10) \\
{[0.033]}\end{array}$ & $\begin{array}{c}16.97^{* *} \\
(2.53) \\
{[0.045]}\end{array}$ & $\begin{array}{c}20.20^{* * *} \\
(3.04) \\
{[0.067]}\end{array}$ & $\begin{array}{c}23.43^{* * *} \\
(3.60) \\
{[0.096]}\end{array}$ & $\begin{array}{c}30.93^{* * *} \\
(4.67) \\
{[0.153]}\end{array}$ & $\begin{array}{c}27.38^{* * *} \\
(4.40) \\
{[0.125]}\end{array}$ & $\begin{array}{c}31.89^{* * *} \\
(4.59) \\
{[0.164]}\end{array}$ \\
\hline$R R E L$ & $\begin{array}{c}18.27^{* * *} \\
(2.93) \\
{[0.035]}\end{array}$ & $\begin{array}{c}21.00^{* * *} \\
(2.77) \\
{[0.045]}\end{array}$ & $\begin{array}{c}23.37^{* * *} \\
(2.68) \\
{[0.047]}\end{array}$ & $\begin{array}{c}35.42^{* * *} \\
(3.14) \\
{[0.082]}\end{array}$ & $\begin{array}{c}49.52^{* * * *} \\
(4.08) \\
{[0.144]}\end{array}$ & $\begin{array}{c}54.30^{* * * *} \\
(4.47) \\
{[0.165]}\end{array}$ & $\begin{array}{c}65.94^{* * *} \\
(5.45) \\
{[0.223]}\end{array}$ & $\begin{array}{c}75.37^{* * *} \\
(5.52) \\
{[0.281]}\end{array}$ & $\begin{array}{c}82.65^{* * *} \\
(4.95) \\
{[0.312]}\end{array}$ & $\begin{array}{c}87.25^{* * *} \\
(5.62) \\
{[0.308]}\end{array}$ & $\begin{array}{c}86.45^{* * *} \\
(5.04) \\
{[0.259]}\end{array}$ & $\begin{array}{c}86.51^{* * *} \\
(4.87) \\
{[0.196]}\end{array}$ \\
\hline$H F \_R E T$ & $\begin{array}{c}-0.35 \\
(-0.08) \\
{[0.000]}\end{array}$ & $\begin{array}{c}0.17 \\
(0.04) \\
{[0.000]}\end{array}$ & $\begin{array}{c}-7.08 \\
(-1.45) \\
{[0.016]}\end{array}$ & $\begin{array}{l}7.88 \\
(1.24) \\
{[0.015]}\end{array}$ & $\begin{array}{c}1.71 \\
(0.28) \\
{[0.001]}\end{array}$ & $\begin{array}{c}2.97 \\
(0.45) \\
{[0.002]}\end{array}$ & $\begin{array}{l}-8.23 \\
(-1.23) \\
{[0.015]}\end{array}$ & $\begin{array}{l}-0.19 \\
(-0.03) \\
{[0.000]}\end{array}$ & $\begin{array}{l}-1.34 \\
(-0.29) \\
{[0.000]}\end{array}$ & $\begin{array}{l}-4.21 \\
(-1.01) \\
{[0.005]}\end{array}$ & $\begin{array}{l}-9.82^{*} \\
(-1.65) \\
{[0.025]}\end{array}$ & $\begin{array}{l}-3.32 \\
(-0.62) \\
{[0.003]}\end{array}$ \\
\hline$H F_{-}$ & $\begin{array}{l}-1.81 \\
(-0.10) \\
{[0.000]}\end{array}$ & $\begin{array}{l}21.39 \\
(1.04) \\
{[0.006]}\end{array}$ & $\begin{array}{c}8.48 \\
(0.35) \\
{[0.001]}\end{array}$ & $\begin{array}{l}34.14 \\
(1.40) \\
{[0.010]}\end{array}$ & $\begin{array}{l}47.56 \\
(1.56) \\
{[0.018]}\end{array}$ & $\begin{array}{l}55.10 \\
(1.61) \\
{[0.024]}\end{array}$ & $\begin{array}{l}67.01^{*} \\
(1.93) \\
{[0.035]}\end{array}$ & $\begin{array}{c}86.95^{* *} \\
(2.26) \\
{[0.062]}\end{array}$ & $\begin{array}{c}93.40^{* *} \\
(2.32) \\
{[0.077]}\end{array}$ & $\begin{array}{c}94.78^{* * *} \\
(2.72) \\
{[0.077]}\end{array}$ & $\begin{array}{c}92.44^{* * *} \\
(2.61) \\
{[0.074]}\end{array}$ & $\begin{array}{c}87.36^{* * *} \\
(2.60) \\
{[0.068]}\end{array}$ \\
\hline$H F \_S K E W$ & $\begin{array}{l}-0.01 \\
(-0.08) \\
{[0.000]}\end{array}$ & $\begin{array}{c}0.00 \\
(-0.02) \\
{[0.000]}\end{array}$ & $\begin{array}{c}0.12 \\
(0.65) \\
{[0.004]}\end{array}$ & $\begin{array}{c}0.12 \\
(0.58) \\
{[0.003]}\end{array}$ & $\begin{array}{c}0.11 \\
(0.52) \\
{[0.003]}\end{array}$ & $\begin{array}{c}0.18 \\
(0.74) \\
{[0.006]}\end{array}$ & & & & $\begin{array}{c}0.05 \\
(0.27) \\
{[0.001]}\end{array}$ & & $\begin{array}{c}0.21 \\
(1.14) \\
{[0.011]}\end{array}$ \\
\hline$H F_{-} E$ & $\begin{array}{l}-0.76 \\
(-1.23) \\
{[0.004]}\end{array}$ & $\begin{array}{l}-0.10 \\
(-0.19) \\
{[0.000]}\end{array}$ & $\begin{array}{c}0.06 \\
(0.04) \\
{[0.000]}\end{array}$ & $\begin{array}{c}-0.92 \\
(-0.84) \\
{[0.004]}\end{array}$ & $\begin{array}{l}-0.48 \\
(-0.45) \\
{[0.001]}\end{array}$ & $\begin{array}{c}0.39 \\
(0.27) \\
{[0.001]}\end{array}$ & $\begin{array}{c}0.47 \\
(0.31) \\
{[0.001]}\end{array}$ & $\begin{array}{l}-1.18 \\
(-1.05) \\
{[0.007]}\end{array}$ & $\begin{array}{l}-1.47 \\
(-1.07) \\
{[0.012]}\end{array}$ & $\begin{array}{l}-0.17 \\
(-0.13) \\
{[0.000]}\end{array}$ & $\begin{array}{l}-2.08 \\
(-1.52) \\
{[0.023]}\end{array}$ & $\begin{array}{l}-2.00 \\
(-1.36) \\
{[0.021]}\end{array}$ \\
\hline$M K T \_R E T$ & $\begin{array}{l}1.05 \\
(0.85) \\
{[0.004]}\end{array}$ & $\begin{array}{l}2.39^{*} \\
(1.71) \\
{[0.019]}\end{array}$ & $\begin{array}{c}5.11^{* * *} \\
(3.60) \\
{[0.071]}\end{array}$ & $\begin{array}{c}-0.66 \\
(-0.38) \\
{[0.001]}\end{array}$ & $\begin{array}{c}0.33 \\
(0.23) \\
{[0.000]}\end{array}$ & $\begin{array}{c}1.19 \\
(0.67) \\
{[0.003]}\end{array}$ & $\begin{array}{c}2.96 \\
(1.47) \\
{[0.018]}\end{array}$ & $\begin{array}{c}1.09 \\
(0.71) \\
{[0.003]}\end{array}$ & $\begin{array}{c}0.22 \\
(0.14) \\
{[0.000]}\end{array}$ & $\begin{array}{c}1.79 \\
(1.42) \\
{[0.008]}\end{array}$ & $\begin{array}{l}3.71^{* *} \\
(2.21) \\
{[0.033]}\end{array}$ & $\begin{array}{c}2.88^{* *} \\
(2.19) \\
{[0.020]}\end{array}$ \\
\hline$M K T_{-} V O L$ & $\begin{array}{c}-5.60^{* *} \\
(-2.54) \\
{[0.037]}\end{array}$ & $\begin{array}{l}-4.41 \\
(-1.42) \\
{[0.023]}\end{array}$ & $\begin{array}{c}-7.31^{* * *} \\
(-2.94) \\
{[0.052]}\end{array}$ & $\begin{array}{l}-1.97 \\
(-0.65) \\
{[0.003]}\end{array}$ & $\begin{array}{l}-3.25 \\
(-0.91) \\
{[0.008]}\end{array}$ & $\begin{array}{l}-2.95 \\
(-0.97) \\
{[0.007]}\end{array}$ & $\begin{array}{l}-5.05^{*} \\
(-1.80) \\
{[0.019]}\end{array}$ & $\begin{array}{c}1.63 \\
(0.52) \\
{[0.002]}\end{array}$ & $\begin{array}{l}-0.21 \\
(-0.06) \\
{[0.000]}\end{array}$ & $\begin{array}{c}0.38 \\
(0.12) \\
{[0.000]}\end{array}$ & $\begin{array}{l}-1.68 \\
(-0.71) \\
{[0.002]}\end{array}$ & $\begin{array}{l}-2.63 \\
(-0.97) \\
{[0.006]}\end{array}$ \\
\hline CORR & $\begin{array}{c}0.76 \\
(0.38) \\
{[0.001]}\end{array}$ & $\begin{array}{l}-1.23 \\
(-0.69) \\
{[0.002]}\end{array}$ & $\begin{array}{c}0.10 \\
(0.05) \\
{[0.000]}\end{array}$ & $\begin{array}{l}-0.04 \\
(-0.02) \\
{[0.000]}\end{array}$ & $\begin{array}{l}-1.08 \\
(-0.40) \\
{[0.001]}\end{array}$ & $\begin{array}{l}-1.86 \\
(-0.64) \\
{[0.003]}\end{array}$ & $\begin{array}{l}-3.07 \\
(-1.00) \\
{[0.008]}\end{array}$ & $\begin{array}{l}-3.72 \\
(-1.20) \\
{[0.013]}\end{array}$ & $\begin{array}{l}-2.72 \\
(-0.83) \\
{[0.007]}\end{array}$ & $\begin{array}{l}-3.71 \\
(-1.21) \\
{[0.013]}\end{array}$ & $\begin{array}{l}-1.86 \\
(-0.57) \\
{[0.003]}\end{array}$ & $\begin{array}{l}-0.27 \\
(-0.09) \\
{[0.000]}\end{array}$ \\
\hline$Z E$ & $\begin{array}{l}-0.29 \\
(-1.10) \\
{[0.005]}\end{array}$ & $\begin{array}{c}0.02 \\
(0.05) \\
{[0.000]}\end{array}$ & $\begin{array}{l}-0.47 \\
(-1.37) \\
{[0.010]}\end{array}$ & $\begin{array}{l}-0.06 \\
(-0.15) \\
{[0.000]}\end{array}$ & $\begin{array}{c}0.04 \\
(0.10) \\
{[0.000]}\end{array}$ & $\begin{array}{c}0.05 \\
(0.13) \\
{[0.000]}\end{array}$ & $\begin{array}{c}0.04 \\
(0.10) \\
{[0.000]}\end{array}$ & $\begin{array}{c}0.55 \\
(1.17) \\
{[0.011]}\end{array}$ & $\begin{array}{c}0.43 \\
(0.91) \\
{[0.008]}\end{array}$ & $\begin{array}{c}0.50 \\
(1.13) \\
{[0.010]}\end{array}$ & $\begin{array}{c}0.20 \\
(0.44) \\
{[0.002]}\end{array}$ & $\begin{array}{l}-0.02 \\
(-0.04) \\
{[0.000]}\end{array}$ \\
\hline Adjusted $R^{2}$ & 0.71 & 0.71 & 0.66 & 0.56 & 0.54 & 0.53 & 0.53 & 0.56 & 0.60 & 0.58 & 0.59 & 0.59 \\
\hline
\end{tabular}

This table reports the coefficients from the $n$-month-ahead predictive regressions of $C F N A I$ on aggregate MES where $n$ ranges from 1 to 12 . The variable AMES is the aggregate MES calculated as the equalweighted average of all hedge funds' MES and the control variables are defined as follows: $D E F$ is the difference between the BAA-rated and AAA-rated corporate bonds; TERM is the difference between the ten-year T-bond and one-month T-bill yields; $R R E L$ is the difference between the one-month T-bill rate and its twelve-month backward-moving average; $H F \_R E T$ is the equal-weighted average excess returns of all hedge funds; $H F_{-} V O L$ is the rolling monthly volatility of excess returns of all hedge funds over the past five years; $H F_{-} S K E W$ is the rolling monthly skewness of excess returns of all hedge funds over the past five years; $H F_{-} B E T A$ is the average market beta of all hedge funds estimated from monthly returns over the past five years; $M K T \_R E T$ is the monthly excess return on the CRSP value-weighted index; $M K T_{-} V O L$ is the realized monthly volatility of excess returns of the aggregate stock market portfolio; $C O R R$ is the average correlation between excess returns on individual hedge funds and excess returns on the financial market index over the past five years; and $S I Z E$ is the natural logarithm of the monthly AUM of hedge funds. For brevity, the coefficient estimates for the twelve lags of the dependent variable $\left(C F N A I_{t+n}\right)$ are omitted. The sample period is from January 1994 to December 2012. Newey-West $t$-statistics are reported in the parenthesis. The partial $R^{2}$ values are reported in the brackets. The adjusted $R^{2}$ values are reported in the last row. ${ }^{*},{ }^{* *}$, and ${ }^{* * *}$ indicate significance at the $10 \%, 5 \%$, and $1 \%$ level, respectively. 
Table 5

Univariate decile portfolios of hedge funds sorted by MES.

\begin{tabular}{|c|c|c|c|c|c|c|c|c|c|c|c|}
\hline & \multicolumn{10}{|c|}{ MES deciles } & \multirow[b]{2}{*}{$1-10$} \\
\hline & 1 & 2 & 3 & 4 & 5 & 6 & 7 & 8 & 9 & 10 & \\
\hline \multicolumn{12}{|c|}{ Panel A: All funds $(N=5771)$} \\
\hline $\operatorname{MES}(\%)$ & -12.95 & -6.42 & -4.19 & -2.89 & -2.01 & -1.35 & -0.76 & -0.20 & 0.58 & 3.98 & \\
\hline Size $(\$$ bn $)$ & 107.81 & 145.53 & 155.16 & 171.73 & 186.35 & 199.81 & 227.88 & 244.47 & 237.46 & 237.61 & \\
\hline \multirow[t]{2}{*}{ Alpha (\%) } & 0.69 & 0.32 & 0.25 & 0.26 & 0.20 & 0.20 & 0.18 & 0.16 & 0.17 & 0.04 & $0.64^{* * *}$ \\
\hline & $(3.55)$ & $(2.67)$ & $(2.40)$ & $(2.55)$ & $(2.42)$ & $(2.42)$ & $(2.37)$ & $(2.26)$ & $(2.19)$ & $(0.36)$ & $(2.92)$ \\
\hline \multicolumn{12}{|c|}{ Panel B: Live funds $(N=1799)$} \\
\hline $\operatorname{MES}(\%)$ & -13.35 & -6.47 & -4.31 & -3.09 & -2.21 & -1.54 & -0.92 & -0.33 & 0.42 & 3.15 & \\
\hline Size $(\$$ bn $)$ & 102.22 & 133.51 & 167.28 & 188.52 & 220.76 & 228.57 & 258.47 & 264.43 & 273.26 & 273.79 & \\
\hline \multirow[t]{2}{*}{ Alpha (\%) } & 1.17 & 0.54 & 0.44 & 0.42 & 0.34 & 0.34 & 0.25 & 0.32 & 0.30 & 0.35 & $0.82^{* * *}$ \\
\hline & $(4.30)$ & $(3.81)$ & $(3.53)$ & $(3.54)$ & $(3.33)$ & $(4.09)$ & $(2.80)$ & $(3.39)$ & $(3.79)$ & $(2.99)$ & $(3.19)$ \\
\hline \multicolumn{12}{|c|}{ Panel C: Defunct funds $(N=3972)$} \\
\hline $\operatorname{MES}(\%)$ & -12.41 & -6.22 & -4.07 & -2.76 & -1.90 & -1.24 & -0.68 & -0.14 & 0.65 & 4.32 & \\
\hline Size $(\$$ bn $)$ & 103.32 & 138.44 & 131.49 & 135.37 & 149.55 & 169.83 & 189.90 & 204.50 & 190.29 & 174.57 & \\
\hline \multirow[t]{2}{*}{ Alpha (\%) } & 0.32 & 0.10 & 0.07 & 0.11 & 0.10 & 0.07 & 0.09 & 0.04 & 0.04 & -0.22 & $0.54^{* *}$ \\
\hline & $(1.62)$ & $(0.82)$ & $(0.59)$ & $(1.02)$ & $(1.14)$ & $(0.71)$ & $(1.10)$ & $(0.64)$ & $(0.38)$ & $(-1.62)$ & $(2.52)$ \\
\hline \multicolumn{12}{|c|}{ Panel D: Liquidated funds $(N=1762)$} \\
\hline $\operatorname{MES}(\%)$ & -11.22 & -5.63 & -3.72 & -2.58 & -1.81 & -1.20 & -0.66 & -0.12 & 0.66 & 4.27 & \\
\hline Size $(\$$ bn $)$ & 65.30 & 72.98 & 86.92 & 88.39 & 97.46 & 118.91 & 139.60 & 141.13 & 148.33 & 130.71 & \\
\hline \multirow[t]{2}{*}{ Alpha (\%) } & 0.25 & -0.02 & -0.04 & 0.13 & 0.08 & 0.06 & 0.03 & -0.03 & -0.05 & -0.40 & $0.64^{* * *}$ \\
\hline & $(1.17)$ & $(-0.13)$ & $(-0.35)$ & $(1.07)$ & $(0.93)$ & $(0.62)$ & $(0.32)$ & $(-0.35)$ & $(-0.53)$ & $(-2.70)$ & $(2.58)$ \\
\hline
\end{tabular}

This table presents the average value of the MES, size, and one-month-ahead risk-adjusted returns for each MES portfolio for all, live, defunct, and liquidated funds. The MES portfolios are formed every month from January 1999 to December 2012 by sorting hedge funds based on their MES. Decile 1 is the portfolio of hedge funds with the lowest MES (the systemically riskiest portfolio) and decile 10 is the portfolio of hedge funds with the highest MES (the least systemically risky portfolio). We also report the average size of the MES portfolio as the monthly AUM in billions of dollars. To compute risk-adjusted portfolio returns, we employ the Fung and Hsieh (2004) seven-factor model and use the Fung-Hsieh alpha as the risk-adjusted return. The last column presents the average alpha difference between deciles 1 and 10. Newey-West $t$-statistics are reported in the parenthesis. ${ }^{*},{ }^{* *}$, and ${ }^{* * *}$ indicate significance at the $10 \%, 5 \%$, and $1 \%$ level, respectively. 
Table 6

Panel regressions of one-month-ahead hedge fund returns on MES, with and without control variables.

\begin{tabular}{|c|c|c|c|c|c|c|c|c|}
\hline & \multicolumn{4}{|c|}{ Return } & \multicolumn{4}{|c|}{ Unsmoothed return } \\
\hline & (1) & (2) & (3) & (4) & (5) & (6) & (7) & (8) \\
\hline Intercept & $\begin{array}{l}0.27^{*} \\
(1.81)\end{array}$ & $\begin{array}{l}-0.02 \\
(-0.13)\end{array}$ & $\begin{array}{l}0.39^{* *} \\
(2.30)\end{array}$ & $\begin{array}{l}0.15 \\
(0.73)\end{array}$ & $\begin{array}{c}0.25 \\
(1.48)\end{array}$ & $\begin{array}{c}-0.03 \\
(-0.15)\end{array}$ & $\begin{array}{c}0.34 \\
(1.51)\end{array}$ & $\begin{array}{c}0.12 \\
(0.45)\end{array}$ \\
\hline$M E S$ & $\begin{array}{c}-8.03^{* * *} \\
(-3.80)\end{array}$ & $\begin{array}{c}-8.05^{* * *} \\
(-3.85)\end{array}$ & $\begin{array}{c}-8.12^{* * * *} \\
(-3.86)\end{array}$ & $\begin{array}{c}-8.25^{* * *} \\
(-3.94)\end{array}$ & $\begin{array}{c}-6.85^{* * *} \\
(-3.27)\end{array}$ & $\begin{array}{c}-6.87^{* * *} \\
(-3.31)\end{array}$ & $\begin{array}{c}-6.89^{* * *} \\
(-3.35)\end{array}$ & $\begin{array}{c}-6.98^{* * *} \\
(-3.41)\end{array}$ \\
\hline$A G E$ & & $\begin{array}{l}-0.00 \\
(-1.55)\end{array}$ & & $\begin{array}{l}-0.00 \\
(-1.43)\end{array}$ & & $\begin{array}{l}-0.00 \\
(-1.27)\end{array}$ & & $\begin{array}{l}-0.00 \\
(-1.17)\end{array}$ \\
\hline SIZE & & $\begin{array}{c}-0.02 \\
(-0.50)\end{array}$ & & $\begin{array}{l}-0.03 \\
(-0.71)\end{array}$ & & $\begin{array}{l}-0.05 \\
(-0.95)\end{array}$ & & $\begin{array}{l}-0.06 \\
(-1.11)\end{array}$ \\
\hline MGMTFEE & & $\begin{array}{c}0.04 \\
(1.26)\end{array}$ & & $\begin{array}{c}0.03 \\
(1.25)\end{array}$ & & $\begin{array}{c}0.03 \\
(0.94)\end{array}$ & & $\begin{array}{c}0.03 \\
(0.97)\end{array}$ \\
\hline ICTFEE & & $\begin{array}{c}0.01^{* * *} \\
(5.24)\end{array}$ & & $\begin{array}{l}0.01^{* *} \\
(2.25)\end{array}$ & & $\begin{array}{c}0.01^{* * *} \\
(4.54)\end{array}$ & & $\begin{array}{l}0.01^{* *} \\
(2.11)\end{array}$ \\
\hline$R E D E M P$ & & $\begin{array}{l}0.00^{*} \\
(1.92)\end{array}$ & & $\begin{array}{l}0.00^{* *} \\
(2.25)\end{array}$ & & $\begin{array}{l}0.00^{*} \\
(1.65)\end{array}$ & & $\begin{array}{l}0.00^{* *} \\
(2.01)\end{array}$ \\
\hline MININVEST & & $\begin{array}{l}0.01^{*} \\
(1.85)\end{array}$ & & $\begin{array}{l}0.01^{*} \\
(1.69)\end{array}$ & & $\begin{array}{c}0.01 \\
(1.37)\end{array}$ & & $\begin{array}{c}0.01 \\
(1.18)\end{array}$ \\
\hline$D L O C K U P$ & & $\begin{array}{l}0.08^{* *} \\
(2.08)\end{array}$ & & $\begin{array}{l}0.09^{* *} \\
(2.23)\end{array}$ & & $\begin{array}{l}0.08^{*} \\
(1.83)\end{array}$ & & $\begin{array}{l}0.09^{*} \\
(1.85)\end{array}$ \\
\hline$D L E V E R A G E$ & & $\begin{array}{l}0.06^{*} \\
(1.87)\end{array}$ & & $\begin{array}{l}0.05^{*} \\
(1.84)\end{array}$ & & $\begin{array}{l}0.06^{*} \\
(1.79)\end{array}$ & & $\begin{array}{l}0.05^{*} \\
(1.70)\end{array}$ \\
\hline Style fixed effect & No & No & Yes & Yes & No & No & Yes & Yes \\
\hline
\end{tabular}

This table reports the coefficients from the panel regressions of one-month-ahead hedge fund returns on MES, with and without control variables (age, asset size, management fee, incentive fee, redemption notice period, minimum initial investment amount, lockup dummy, and leverage dummy) over the sample period January 1999 to December 2012. A negative coefficient on MES implies a positive systemic risk premium, as low values of MES imply significant systemic risk. While the dependent variable in model (1)-(4) is individual hedge fund return, that in model (5)-(8) is unsmoothed return obtained from the Getmansky, Lo, and Makarov (2004) approach. Model (3), (4), (7), and (8) include style fixed effect. T-statistics clustered by fund and month are reported in the parenthesis. ${ }^{*},{ }^{* *}$, and ${ }^{* *}$ indicate significance at the $10 \%, 5 \%$, and $1 \%$ level, respectively. 


\section{Table 7}

Univariate decile portfolios of hedge funds sorted by MES across different threshold parameters.

\begin{tabular}{|c|c|c|c|c|c|c|c|c|c|c|c|}
\hline & & & & & MES & leciles & & & & & \\
\hline & 1 & 2 & 3 & 4 & 5 & 6 & 7 & 8 & 9 & 10 & $1-10$ \\
\hline Panel A: $C$ & $=-0.05$ & & & & & & & & & & \\
\hline MES (\%) & -6.58 & -3.13 & -1.95 & -1.26 & -0.80 & -0.44 & -0.10 & 0.25 & 0.73 & 2.70 & \\
\hline Alpha (\%) & 0.64 & 0.33 & 0.20 & 0.25 & 0.19 & 0.16 & 0.17 & 0.17 & 0.17 & 0.07 & $0.57^{* *}$ \\
\hline & $(3.30)$ & $(2.62)$ & $(1.87)$ & $(2.49)$ & $(2.14)$ & $(1.95)$ & $(2.37)$ & $(2.56)$ & $(2.15)$ & $(0.61)$ & $(2.51)$ \\
\hline Panel B: $C$ & $=-0.08$ & & & & & & & & & & \\
\hline MES (\%) & -10.88 & -5.34 & -3.45 & -2.35 & -1.62 & -1.05 & -0.56 & -0.07 & 0.61 & 3.54 & \\
\hline Alpha (\%) & 0.68 & 0.33 & 0.27 & 0.20 & 0.22 & 0.19 & 0.19 & 0.17 & 0.17 & 0.05 & $0.63^{* * *}$ \\
\hline & $(3.48)$ & $(2.71)$ & $(2.49)$ & $(2.10)$ & $(2.44)$ & $(2.39)$ & $(2.48)$ & $(2.46)$ & $(2.10)$ & $(0.42)$ & $(2.75)$ \\
\hline Panel C: $C$ & $=-0.10$ & & & & & & & & & & \\
\hline MES (\%) & -12.95 & -6.42 & -4.19 & -2.89 & -2.01 & -1.35 & -0.76 & -0.20 & 0.58 & 3.98 & \\
\hline Alpha (\%) & 0.69 & 0.32 & 0.25 & 0.26 & 0.20 & 0.20 & 0.18 & 0.16 & 0.17 & 0.04 & $0.64^{* * *}$ \\
\hline & $(3.55)$ & $(2.67)$ & $(2.40)$ & $(2.55)$ & $(2.42)$ & $(2.42)$ & $(2.37)$ & $(2.26)$ & $(2.19)$ & $(0.36)$ & $(2.92)$ \\
\hline Panel D: $C$ & $=-0.15$ & & & & & & & & & & \\
\hline $\operatorname{MES}(\%)$ & -16.00 & -8.13 & -5.39 & -3.81 & -2.72 & -1.90 & -1.19 & -0.48 & 0.45 & 4.47 & \\
\hline Alpha (\%) & 0.68 & 0.34 & 0.26 & 0.24 & 0.21 & 0.20 & 0.17 & 0.14 & 0.18 & 0.05 & $0.63^{* * *}$ \\
\hline & $(3.52)$ & $(2.78)$ & $(2.51)$ & $(2.48)$ & $(2.37)$ & $(2.59)$ & $(2.13)$ & (1.95) & $(2.34)$ & $(0.42)$ & $(2.86)$ \\
\hline
\end{tabular}

This table presents the average value of the MES and the one-month-ahead risk-adjusted returns for the MES portfolios across different threshold parameters $(C=-0.05$ in Panel $\mathrm{A}, C=-0.08$ in Panel $\mathrm{B}, C=-0.10$ in Panel $\mathrm{C}$, and $C=-0.15$ in Panel D). The threshold parameter $C$ is used to define a systemic event. We define a systemic event as a drop in the market return below a threshold $C$. The MES portfolios are formed every month from January 1999 to December 2012 by sorting hedge funds based on their MES. Decile 1 is the portfolio of hedge funds with the lowest MES (the systemically riskiest portfolio) and decile 10 is the portfolio of hedge funds with the highest MES (the least systemically risky portfolio). To compute risk-adjusted portfolio returns, we employ the Fung and Hsieh (2004) seven-factor model and use the Fung-Hsieh alpha as the risk-adjusted return. The last column presents the average alpha difference between deciles 1 and 10. Newey-West $t$-statistics are reported in the parenthesis. ${ }^{*},{ }^{* *}$, and ${ }^{* * *}$ indicate significance at the $10 \%, 5 \%$, and $1 \%$ level, respectively. 


\section{Table 8}

Average rolling period correlation between MES and beta.

\begin{tabular}{lcccc}
\hline Panel A: Correlation & MES & ES & Volatility & Beta \\
\hline MES & 1 & 0.49 & -0.46 & -0.78 \\
ES & & 1 & -0.91 & -0.57 \\
Volatility & & & 1 & 0.54 \\
Beta & & & & 1 \\
\hline & MES & ES & Volatility & Beta \\
\hline Panel B: Rank correlation & 1 & 0.50 & -0.46 & -0.80 \\
MES & & 1 & -0.92 & -0.55 \\
ES & & & 1 & 0.52 \\
Volatility & & & & 1 \\
Beta & & & & \\
\hline
\end{tabular}

This table reports the average rolling period correlation coefficients between MES, ES, volatility, and beta of individual hedge funds from January 1999 to December 2012. Panels A and B report the average Pearson and Spearman rank correlation coefficients, respectively. For each updating period in which the ex ante MES is calculated, we first calculate the ES, volatility and CAPM beta for each individual hedge fund and then compute the Pearson and Spearman rank correlation coefficients between the four variables. This process is repeated on a monthly basis and the correlation coefficients are then averaged across the entire sample period. 
Table 9

MES predictions for crisis returns and crisis covariance while controlling for beta and hedge fund volatility.

\begin{tabular}{|c|c|c|c|c|c|c|}
\hline & \multicolumn{3}{|c|}{ U.S. subprime crisis } & \multicolumn{3}{|c|}{ European sovereign debt crisis } \\
\hline & Return & $\begin{array}{c}\text { 3-month } \\
\text { covariance }\end{array}$ & $\begin{array}{c}1 \text {-year } \\
\text { covariance }\end{array}$ & Return & $\begin{array}{l}\text { 3-month } \\
\text { covariance }\end{array}$ & $\begin{array}{c}\text { 1-year } \\
\text { covariance }\end{array}$ \\
\hline Intercept & $\begin{array}{l}-0.08^{* * *} \\
(-11.15)\end{array}$ & $\begin{array}{l}-3.81^{* *} \\
(-1.99)\end{array}$ & $\begin{array}{c}2.16 \\
(1.00)\end{array}$ & $\begin{array}{c}-0.02^{* * *} \\
(-5.05)\end{array}$ & $\begin{array}{c}0.50 \\
(0.62)\end{array}$ & $\begin{array}{l}1.82^{* * *} \\
(2.78)\end{array}$ \\
\hline$M E S$ & $\begin{array}{c}0.26 \\
(0.64)\end{array}$ & $\begin{array}{c}-132.89^{*} \\
(-1.76)\end{array}$ & $\begin{array}{c}-306.86^{* *} \\
(-2.50)\end{array}$ & $\begin{array}{c}0.50^{* * *} \\
(4.55)\end{array}$ & $\begin{array}{c}-72.89^{* * *} \\
(-3.35)\end{array}$ & $\begin{array}{c}-100.79^{* * *} \\
(-4.78)\end{array}$ \\
\hline Beta & $\begin{array}{c}-0.29^{* * *} \\
(-4.91)\end{array}$ & $\begin{array}{c}4.92 \\
(0.42)\end{array}$ & $\begin{array}{c}77.89^{* * *} \\
(4.84)\end{array}$ & $\begin{array}{l}-0.21^{* * *} \\
(-11.34)\end{array}$ & $\begin{array}{l}6.50^{* *} \\
(2.07)\end{array}$ & $\begin{array}{c}55.17^{* * *} \\
(16.03)\end{array}$ \\
\hline Volatility & $\begin{array}{c}-0.01^{* * *} \\
(-4.25)\end{array}$ & $\begin{array}{c}0.34 \\
(1.34)\end{array}$ & $\begin{array}{c}2.58^{* * *} \\
(8.11)\end{array}$ & $\begin{array}{c}0.00 \\
(0.57)\end{array}$ & $\begin{array}{c}0.36^{* * *} \\
(4.31)\end{array}$ & $\begin{array}{c}0.03 \\
(0.41)\end{array}$ \\
\hline Adjusted $R^{2}$ & 0.23 & 0.03 & 0.41 & 0.48 & 0.32 & 0.67 \\
\hline
\end{tabular}

This table reports the coefficients from the regression of the realized crisis return/covariance on the ex ante MES for individual hedge funds while controlling for CAPM beta and hedge fund volatility. Since we do not perform any sign conversion in the estimation of the MES, a significantly negative MES value represents a high systemic risk. For the U.S. subprime crisis, the crisis return and crisis covariance are the realized return and realized covariance for September-November 2008, respectively. The MES is estimated with data as of August 2008. For the European sovereign debt crisis, the crisis return and crisis covariance are the realized return and realized covariance for July-September 2011, respectively. The MES is estimated with data as of June 2011. In the case of the crisis covariance, we also use the realized covariance over one year from the start of each crisis. Newey-West $t$-statistics are reported in the parenthesis. The adjusted $R^{2}$ values are reported in the last row. ${ }^{*},{ }^{* *}$, and ${ }^{* * *}$ indicate significance at the $10 \%, 5 \%$, and $1 \%$ level, respectively. 
Table 10

Univariate decile portfolios of hedge funds sorted by beta.

\begin{tabular}{|c|c|c|c|c|c|c|c|c|c|c|c|}
\hline & \multicolumn{10}{|c|}{ Beta deciles } & \multirow[b]{2}{*}{$1-10$} \\
\hline & 1 & 2 & 3 & 4 & 5 & 6 & 7 & 8 & 9 & 10 & \\
\hline \multicolumn{12}{|c|}{ Panel A: All funds $(N=5771)$} \\
\hline Beta & 0.91 & 0.42 & 0.27 & 0.19 & 0.13 & 0.09 & 0.06 & 0.02 & -0.02 & -0.38 & \\
\hline \multirow[t]{2}{*}{ Alpha $(\%)$} & 0.75 & 0.26 & 0.39 & 0.23 & 0.25 & 0.23 & 0.25 & 0.21 & 0.19 & 0.24 & $0.51^{* *}$ \\
\hline & $(3.59)$ & $(2.32)$ & $(3.30)$ & $(2.45)$ & $(2.79)$ & $(3.05)$ & $(2.73)$ & $(3.52)$ & $(2.80)$ & $(2.23)$ & $(2.43)$ \\
\hline \multicolumn{12}{|c|}{ Panel B: Live funds $(N=1799)$} \\
\hline Beta & 0.94 & 0.43 & 0.28 & 0.20 & 0.14 & 0.10 & 0.06 & 0.03 & -0.02 & -0.36 & \\
\hline \multirow[t]{2}{*}{ Alpha $(\%)$} & 1.09 & 0.42 & 0.68 & 0.35 & 0.38 & 0.36 & 0.33 & 0.36 & 0.34 & 0.56 & $0.53^{* *}$ \\
\hline & $(4.16)$ & $(3.66)$ & $(4.32)$ & $(3.45)$ & $(3.54)$ & $(3.60)$ & $(3.48)$ & $(5.34)$ & $(4.53)$ & $(4.13)$ & $(2.20)$ \\
\hline \multicolumn{12}{|c|}{ Panel C: Defunct funds $(N=3972)$} \\
\hline Beta & 0.86 & 0.39 & 0.25 & 0.18 & 0.13 & 0.08 & 0.05 & 0.02 & -0.03 & -0.38 & \\
\hline \multirow[t]{2}{*}{ Alpha (\%) } & 0.37 & 0.17 & 0.08 & 0.17 & 0.10 & 0.14 & 0.16 & 0.09 & 0.02 & 0.00 & $0.39^{* *}$ \\
\hline & $(1.65)$ & $(1.39)$ & $(0.62)$ & $(1.56)$ & $(1.02)$ & $(1.69)$ & $(2.22)$ & $(1.14)$ & $(0.30)$ & $(-0.02)$ & $(1.97)$ \\
\hline \multicolumn{12}{|c|}{ Panel D: Liquidated funds $(N=1762)$} \\
\hline Beta & 0.78 & 0.34 & 0.23 & 0.17 & 0.12 & 0.08 & 0.05 & 0.02 & -0.03 & -0.39 & \\
\hline \multirow[t]{2}{*}{ Alpha (\%) } & 0.19 & -0.01 & 0.03 & 0.15 & 0.12 & 0.04 & 0.08 & -0.01 & -0.06 & -0.13 & $0.35^{*}$ \\
\hline & $(0.94)$ & $(-0.06)$ & $(0.27)$ & $(1.25)$ & $(1.15)$ & $(0.43)$ & $(0.91)$ & $(-0.17)$ & $(-0.69)$ & $(-1.09)$ & $(1.84)$ \\
\hline
\end{tabular}

This table presents the average value of the CAPM beta and one-month-ahead risk-adjusted returns for each beta portfolio for all, live, defunct, and liquidated funds. The beta portfolios are formed every month from January 1999 to December 2012 by sorting hedge funds based on their CAPM beta. Decile 1 is the portfolio of hedge funds with the highest beta and decile 10 is the portfolio of hedge funds with the lowest beta. To compute risk-adjusted portfolio returns, we employ the Fung and Hsieh (2004) seven-factor model and use the Fung-Hsieh alpha as the risk-adjusted return. The last column presents the average alpha difference between deciles 1 and 10 . Newey-West $t$-statistics are reported in the parenthesis. ${ }^{*},{ }^{* *}$, and $^{* * *}$ indicate significance at the $10 \%, 5 \%$, and $1 \%$ level, respectively. 


\section{Table 11}

Panel regressions of one-month-ahead hedge fund returns on MES and beta, with and without control variables.

\begin{tabular}{|c|c|c|c|c|c|c|c|c|}
\hline & \multicolumn{4}{|c|}{ Return } & \multicolumn{4}{|c|}{ Unsmoothed return } \\
\hline & (1) & $(2)$ & (3) & (4) & (5) & (6) & (7) & (8) \\
\hline \multirow[t]{2}{*}{ Intercept } & $0.26^{* *}$ & -0.02 & $0.38^{* *}$ & 0.14 & $0.24^{*}$ & -0.03 & 0.33 & 0.11 \\
\hline & $(2.30)$ & $(-0.17)$ & $(2.46)$ & $(0.72)$ & (1.88) & $(-0.20)$ & (1.64) & $(0.46)$ \\
\hline \multirow[t]{2}{*}{$M E S$} & $-7.75^{* *}$ & $-7.95^{* * *}$ & $-7.92^{* *}$ & $-8.06^{* * *}$ & $-6.48^{* *}$ & $-6.68^{* *}$ & $-6.61^{* *}$ & $-6.74^{* *}$ \\
\hline & $(-2.53)$ & $(-2.59)$ & $(-2.55)$ & $(-2.60)$ & $(-2.06)$ & $(-2.12)$ & $(-2.08)$ & $(-2.12)$ \\
\hline \multirow[t]{2}{*}{ Beta } & 0.07 & 0.03 & 0.06 & 0.05 & 0.09 & 0.05 & 0.08 & 0.07 \\
\hline & $(0.12)$ & $(0.05)$ & $(0.11)$ & $(0.10)$ & $(0.16)$ & $(0.08)$ & $(0.13)$ & $(0.12)$ \\
\hline \multirow[t]{2}{*}{$A G E$} & & -0.00 & & -0.00 & & -0.00 & & -0.00 \\
\hline & & $(-1.59)$ & & $(-1.47)$ & & $(-1.27)$ & & $(-1.17)$ \\
\hline \multirow[t]{2}{*}{$S I Z E$} & & -0.02 & & -0.03 & & -0.05 & & -0.06 \\
\hline & & $(-0.48)$ & & $(-0.69)$ & & $(-0.92)$ & & $(-1.07)$ \\
\hline \multirow[t]{2}{*}{ MGMTFEE } & & 0.04 & & 0.03 & & 0.03 & & 0.03 \\
\hline & & $(1.26)$ & & $(1.26)$ & & $(0.93)$ & & $(0.96)$ \\
\hline \multirow[t]{2}{*}{ ICTFEE } & & $0.01^{* * *}$ & & $0.01^{* *}$ & & $0.01^{* * *}$ & & $0.01^{* *}$ \\
\hline & & $(4.82)$ & & $(2.32)$ & & $(4.11)$ & & $(2.17)$ \\
\hline \multirow[t]{2}{*}{$R E D E M P$} & & $0.00^{*}$ & & $0.00^{* *}$ & & 0.00 & & $0.00^{* *}$ \\
\hline & & (1.93) & & $(2.25)$ & & $(1.63)$ & & $(2.00)$ \\
\hline \multirow[t]{2}{*}{ MININVEST } & & $0.01^{*}$ & & $0.01^{*}$ & & 0.01 & & 0.01 \\
\hline & & (1.87) & & $(1.70)$ & & $(1.37)$ & & $(1.17)$ \\
\hline \multirow[t]{2}{*}{$D L O C K U P$} & & $0.08^{* *}$ & & $0.09^{* *}$ & & $0.08^{*}$ & & $0.08^{* *}$ \\
\hline & & $(2.20)$ & & $(2.38)$ & & $(1.90)$ & & $(1.97)$ \\
\hline \multirow[t]{2}{*}{$D L E V E R A G E$} & & $0.06^{*}$ & & $0.05^{*}$ & & $0.06^{*}$ & & $0.05^{*}$ \\
\hline & & $(1.88)$ & & $(1.85)$ & & $(1.81)$ & & $(1.72)$ \\
\hline Style fixed effect & No & No & Yes & Yes & No & No & Yes & Yes \\
\hline
\end{tabular}

This table reports the coefficients from the panel regressions of one-month-ahead hedge fund returns on MES and CAPM beta, with and without control variables (age, asset size, management fee, incentive fee, redemption notice period, minimum initial investment amount, lockup dummy, and leverage dummy) over the sample period January 1999 to December 2012. A negative coefficient on MES implies a positive systemic risk premium, as low values of MES imply significant systemic risk. While the dependent variable in model (1)-(4) is individual hedge fund return, that in model (5)-(8) is unsmoothed return obtained from the Getmansky, Lo, and Makarov (2004) approach. Model (3), (4), (7), and (8) include style fixed effect. $T$-statistics clustered by fund and month are reported in the parenthesis. ${ }^{*},{ }^{* *}$, and ${ }^{* * *}$ indicate significance at the $10 \%, 5 \%$, and $1 \%$ level, respectively. 
Table 12

Univariate decile portfolios of hedge funds sorted by MES across different assigned returns.

\begin{tabular}{cccccccccccc}
\hline & \multicolumn{10}{c}{ MES deciles } & \multicolumn{10}{c}{} \\
\cline { 2 - 11 } Assigned return & 1 & 2 & 3 & 4 & 5 & 6 & 7 & 8 & 9 & 10 & $1-10$ \\
\hline One-month-ahead & 0.69 & 0.32 & 0.25 & 0.26 & 0.20 & 0.20 & 0.18 & 0.16 & 0.17 & 0.04 & $0.64^{* * *}$ \\
& $(3.55)$ & $(2.67)$ & $(2.40)$ & $(2.55)$ & $(2.42)$ & $(2.42)$ & $(2.37)$ & $(2.26)$ & $(2.19)$ & $(0.36)$ & $(2.92)$ \\
One-quarter-ahead & 0.61 & 0.32 & 0.26 & 0.24 & 0.19 & 0.18 & 0.21 & 0.18 & 0.13 & 0.01 & $0.60^{* * *}$ \\
& $(3.41)$ & $(2.61)$ & $(2.54)$ & $(2.36)$ & $(1.81)$ & $(1.97)$ & $(2.56)$ & $(2.56)$ & $(2.07)$ & $(0.10)$ & $(3.05)$ \\
Two-quarter-ahead & 0.60 & 0.27 & 0.16 & 0.19 & 0.12 & 0.12 & 0.17 & 0.14 & 0.14 & 0.07 & $0.54^{* *}$ \\
& $(3.04)$ & $(2.39)$ & $(1.51)$ & $(1.80)$ & $(1.19)$ & $(1.38)$ & $(2.16)$ & $(1.95)$ & $(1.95)$ & $(0.68)$ & $(2.54)$ \\
Three-quarter-ahead & 0.55 & 0.22 & 0.16 & 0.14 & 0.13 & 0.15 & 0.16 & 0.14 & 0.18 & 0.12 & $0.43^{* *}$ \\
& $(2.78)$ & $(1.69)$ & $(1.50)$ & $(1.31)$ & $(1.58)$ & $(1.86)$ & $(1.99)$ & $(1.78)$ & $(2.62)$ & $(1.06)$ & $(1.98)$ \\
One-year-ahead & 0.35 & 0.15 & 0.12 & 0.07 & 0.13 & 0.15 & 0.14 & 0.13 & 0.18 & 0.20 & 0.16 \\
& $(2.12)$ & $(1.21)$ & $(1.36)$ & $(0.74)$ & $(1.58)$ & $(1.89)$ & $(1.78)$ & $(1.86)$ & $(2.11)$ & $(1.58)$ & $(0.80)$ \\
\hline
\end{tabular}

This table presents the average value of the risk-adjusted returns (in percent) for the MES portfolios. When portfolio returns are calculated, not only one-month-ahead returns but also one-quarter-ahead, two-quarter-ahead, three-quarter-ahead, and one-year-ahead returns are used. The MES portfolios are formed every month from January 1999 to December 2012 by sorting hedge funds based on their MES. Decile 1 is the portfolio of hedge funds with the lowest MES (the systemically riskiest portfolio) and decile 10 is the portfolio of hedge funds with the highest MES (the least systemically risky portfolio). To compute risk-adjusted portfolio returns, we employ the Fung and Hsieh (2004) seven-factor model and use the Fung-Hsieh alpha as the risk-adjusted return. The last column presents the average alpha difference between deciles 1 and 10. Newey-West $t$-statistics are reported in the parenthesis. ${ }^{*},{ }^{* *}$, and *** indicate significance at the $10 \%, 5 \%$, and $1 \%$ level, respectively. 
Table 13

Univariate decile portfolios of hedge funds sorted by MES across different holding periods.

\begin{tabular}{lcccccccccccc}
\hline & \multicolumn{10}{c}{ MES deciles } & & \\
Holding period & 1 & 2 & 3 & 4 & 5 & 6 & 7 & 8 & 9 & 10 & $1-10$ \\
\hline & 15.33 & 9.28 & 7.58 & 7.00 & 6.17 & 5.90 & 5.54 & 5.09 & 5.49 & 3.97 & $10.96^{* *}$ \\
One month & $(2.64)$ & $(2.53)$ & $(2.69)$ & $(3.11)$ & $(3.26)$ & $(3.52)$ & $(3.78)$ & $(3.86)$ & $(3.98)$ & $(2.60)$ & $(2.03)$ \\
& Three months & 16.22 & 9.37 & 8.19 & 7.70 & 7.16 & 6.15 & 5.65 & 5.53 & 5.49 & 4.69 & $11.14^{* *}$ \\
& $(2.60)$ & $(2.23)$ & $(2.50)$ & $(2.86)$ & $(2.83)$ & $(2.95)$ & $(2.95)$ & $(3.55)$ & $(4.13)$ & $(3.24)$ & $(1.99)$ \\
Six months & 15.73 & 9.85 & 8.55 & 8.52 & 7.31 & 6.44 & 5.89 & 6.26 & 5.42 & 4.23 & $11.28^{* *}$ \\
& $(2.99)$ & $(2.80)$ & $(2.83)$ & $(2.94)$ & $(2.91)$ & $(3.09)$ & $(2.77)$ & $(3.74)$ & $(4.17)$ & $(3.20)$ & $(2.25)$ \\
\multirow{2}{*}{12 months } & 17.47 & 11.30 & 8.76 & 8.84 & 7.34 & 6.94 & 6.62 & 6.44 & 6.69 & 5.24 & $12.23^{* * *}$ \\
& $(3.85)$ & $(3.53)$ & $(3.61)$ & $(3.08)$ & $(3.43)$ & $(3.44)$ & $(3.32)$ & $(4.21)$ & $(5.28)$ & $(3.76)$ & $(2.62)$ \\
\hline
\end{tabular}

This table presents the average value of various holding period returns (in percent, annualized) for the MES portfolios. The MES portfolios are formed from January 1999 to December 2012 by sorting hedge funds based on their MES. The portfolios use non-overlapping returns. For example, for the three-month holding period case, hedge funds are sorted in the beginning of January, April, July, and October. Decile 1 is the portfolio of hedge funds with the lowest MES (the systemically riskiest portfolio) and decile 10 is the portfolio of hedge funds with the highest MES (the least systemically risky portfolio). The last column presents the average return difference between deciles 1 and 10 . Newey-West $t$-statistics are reported in the parenthesis. ${ }^{*},{ }^{* *}$, and ${ }^{* * *}$ indicate significance at the $10 \%, 5 \%$, and $1 \%$ level, respectively. 


\section{Table 14}

Univariate decile portfolios of hedge funds sorted by MES over crisis and non-crisis periods.

\begin{tabular}{|c|c|c|c|c|c|c|c|c|c|c|c|c|}
\hline \multicolumn{6}{|c|}{ Panel A: Monthly returns } & \multicolumn{6}{|c|}{ MES deciles } & \multirow[b]{2}{*}{$1-10$} \\
\hline Period & Months & 1 & 2 & 3 & 4 & 5 & 6 & 7 & 8 & 9 & 10 & \\
\hline All & 168 & $\begin{array}{l}1.20 \\
(2.64)\end{array}$ & $\begin{array}{c}0.74 \\
(2.53)\end{array}$ & $\begin{array}{c}0.61 \\
(2.69)\end{array}$ & $\begin{array}{c}0.57 \\
(3.11)\end{array}$ & $\begin{array}{c}0.50 \\
(3.26)\end{array}$ & $\begin{array}{c}0.48 \\
(3.52)\end{array}$ & $\begin{array}{c}0.45 \\
(3.78)\end{array}$ & $\begin{array}{c}0.41 \\
(3.86)\end{array}$ & $\begin{array}{c}0.45 \\
(3.98)\end{array}$ & $\begin{array}{c}0.32 \\
(2.60)\end{array}$ & $\begin{array}{l}0.87^{* *} \\
(2.03)\end{array}$ \\
\hline $\begin{array}{l}\text { Non-crisis } \\
\text { periods }\end{array}$ & 162 & $\begin{array}{l}1.58 \\
(3.97)\end{array}$ & $\begin{array}{c}0.99 \\
(3.89)\end{array}$ & $\begin{array}{c}0.80 \\
(4.12)\end{array}$ & $\begin{array}{c}0.73 \\
(4.83)\end{array}$ & $\begin{array}{c}0.65 \\
(5.44)\end{array}$ & $\begin{array}{c}0.61 \\
(5.97)\end{array}$ & $\begin{array}{c}0.56 \\
(6.17)\end{array}$ & $\begin{array}{c}0.52 \\
(7.11)\end{array}$ & $\begin{array}{c}0.54 \\
(6.31)\end{array}$ & $\begin{array}{c}0.38 \\
(3.42)\end{array}$ & $\begin{array}{c}1.19^{* * *} \\
(3.02)\end{array}$ \\
\hline $\begin{array}{l}\text { Crisis } \\
\text { periods }\end{array}$ & 6 & $\begin{array}{c}-9.12 \\
(-5.13)\end{array}$ & $\begin{array}{c}-5.94 \\
(-4.93)\end{array}$ & $\begin{array}{c}-4.50 \\
(-3.77)\end{array}$ & $\begin{array}{c}-3.83 \\
(-4.50)\end{array}$ & $\begin{array}{c}-3.49 \\
(-3.97)\end{array}$ & $\begin{array}{l}-3.04 \\
(-3.13)\end{array}$ & $\begin{array}{c}-2.46 \\
(-2.55)\end{array}$ & $\begin{array}{c}-2.52 \\
(-2.75)\end{array}$ & $\begin{array}{c}-2.12 \\
(-2.04)\end{array}$ & $\begin{array}{c}-1.23 \\
(-1.22)\end{array}$ & $\begin{array}{c}-7.89^{* * *} \\
(-8.34)\end{array}$ \\
\hline \multicolumn{6}{|c|}{ Panel B: Three-month cumulative returns } & \multicolumn{3}{|c|}{ MES deciles } & & & & \\
\hline Period & Quarters & 1 & 2 & 3 & 4 & 5 & 6 & 7 & 8 & 9 & 10 & $1-10$ \\
\hline All & 56 & $\begin{array}{c}3.83 \\
(2.60)\end{array}$ & $\begin{array}{c}2.26 \\
(2.23)\end{array}$ & $\begin{array}{c}1.99 \\
(2.50)\end{array}$ & $\begin{array}{c}1.87 \\
(2.86)\end{array}$ & $\begin{array}{c}1.74 \\
(2.83)\end{array}$ & $\begin{array}{c}1.50 \\
(2.95)\end{array}$ & $\begin{array}{c}1.38 \\
(2.95)\end{array}$ & $\begin{array}{c}1.35 \\
(3.55)\end{array}$ & $\begin{array}{c}1.34 \\
(4.13)\end{array}$ & $\begin{array}{c}1.15 \\
(3.24)\end{array}$ & $\begin{array}{l}2.68^{* *} \\
(1.99)\end{array}$ \\
\hline $\begin{array}{l}\text { Non-crisis } \\
\text { periods }\end{array}$ & 53 & $\begin{array}{c}5.02 \\
(3.95)\end{array}$ & $\begin{array}{c}3.10 \\
(3.62)\end{array}$ & $\begin{array}{c}2.67 \\
(4.12)\end{array}$ & $\begin{array}{c}2.48 \\
(5.00)\end{array}$ & $\begin{array}{c}2.29 \\
(4.83)\end{array}$ & $\begin{array}{c}1.99 \\
(5.66)\end{array}$ & $\begin{array}{c}1.88 \\
(6.29)\end{array}$ & $\begin{array}{c}1.78 \\
(8.37)\end{array}$ & $\begin{array}{c}1.70 \\
(8.72)\end{array}$ & $\begin{array}{c}1.44 \\
(4.95)\end{array}$ & $\begin{array}{c}3.58^{* * *} \\
(2.81)\end{array}$ \\
\hline $\begin{array}{l}\text { Crisis } \\
\text { periods }\end{array}$ & 2 & $\begin{array}{c}-23.99 \\
(-10.32)\end{array}$ & $\begin{array}{c}-15.44 \\
(-10.99)\end{array}$ & $\begin{array}{l}-12.23 \\
(-9.04)\end{array}$ & $\begin{array}{l}-10.68 \\
(-8.81)\end{array}$ & $\begin{array}{c}-9.45 \\
(-5.63)\end{array}$ & $\begin{array}{l}-8.89 \\
(-4.62)\end{array}$ & $\begin{array}{c}-8.16 \\
(-4.64)\end{array}$ & $\begin{array}{c}-7.24 \\
(-4.02)\end{array}$ & $\begin{array}{c}-6.19 \\
(-3.35)\end{array}$ & $\begin{array}{c}-4.16 \\
(-2.08)\end{array}$ & $\begin{array}{r}-19.84^{* * *} \\
(-60.95)\end{array}$ \\
\hline
\end{tabular}

This table presents the average value of the returns (in percent) for the MES portfolios over the entire sample period, as well as separately for crisis and non-crisis periods. Crisis periods are from September to November of 2008 (the U.S. subprime crisis) and from July to September of 2011 (the European sovereign debt crisis). Panel A reports the monthly returns for portfolios rebalanced monthly and Panel B reports the three-month non-overlapping cumulative returns for portfolios rebalanced quarterly. The quarterly returns of the non-crisis quarters include all calendar quarters non-overlapping with crisis periods. The MES portfolios are formed from January 1999 to December 2012 by sorting hedge funds based on their MES. Decile 1 is the portfolio of hedge funds with the lowest MES (the systemically riskiest portfolio) and decile 10 is the portfolio of hedge funds with the highest MES (the least systemically risky portfolio). The last column presents the average return difference between deciles 1 and 10 . Newey-West $t$-statistics are reported in the parenthesis. ${ }^{*},{ }^{* *}$, and ${ }^{* * *}$ indicate significance at the $10 \%, 5 \%$, and $1 \%$ level, respectively. 


\section{Figures}
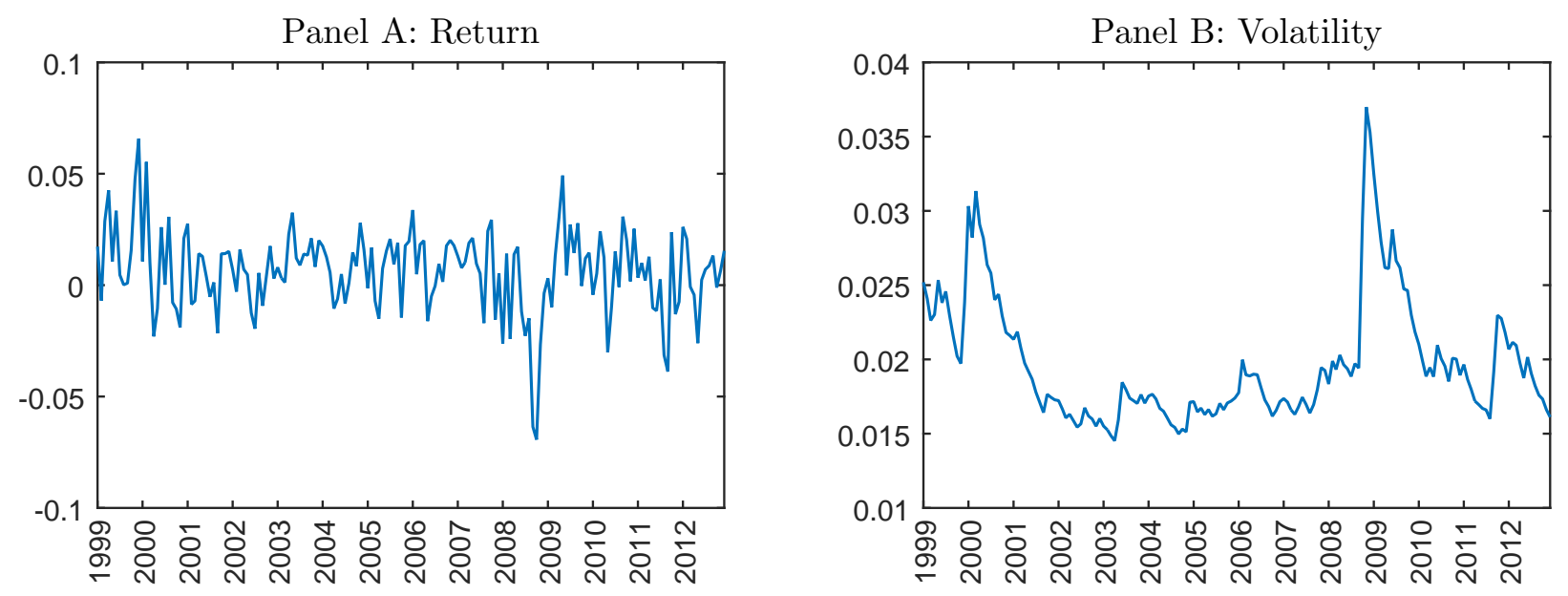

Panel C: Correlation
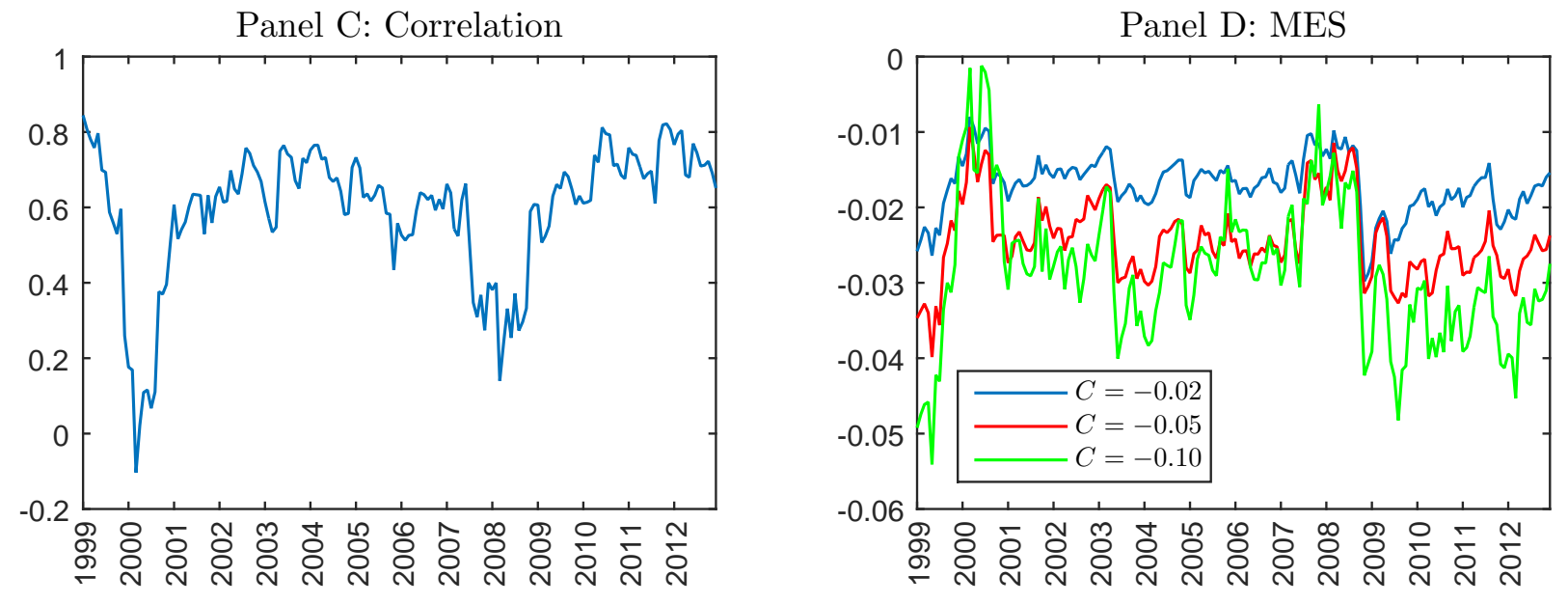

Fig. 1. In-sample MES analysis (January 1999 to December 2012). This figure plots the return (Panel A), volatility (Panel B), correlation (Panel C), and MES (Panel D for various thresholds $C$ ) for the EWHF portfolio in our sample. 
Panel A: One-month holding period

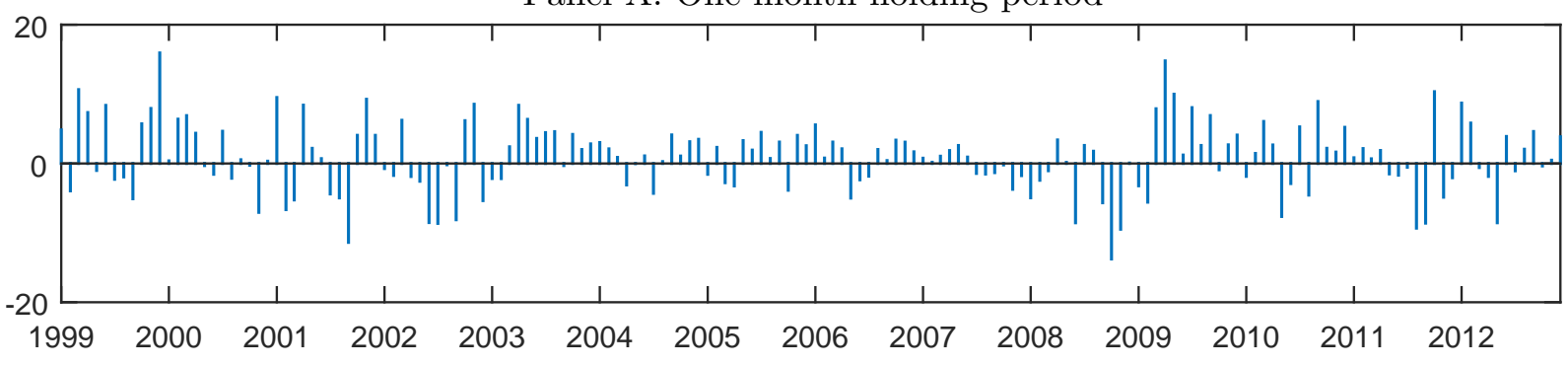

Panel B: Three-month holding period

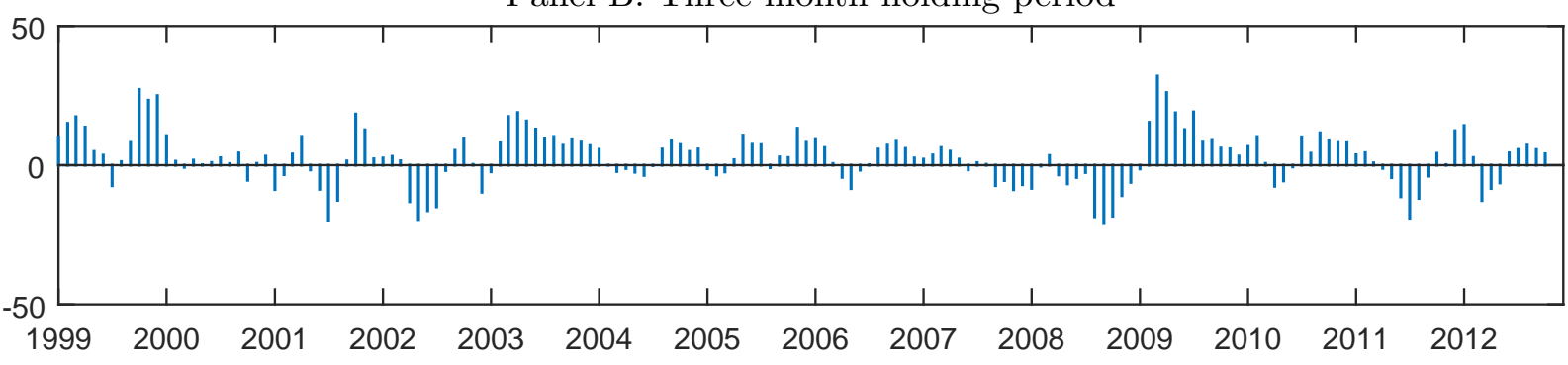

Panel C: Six-month holding period

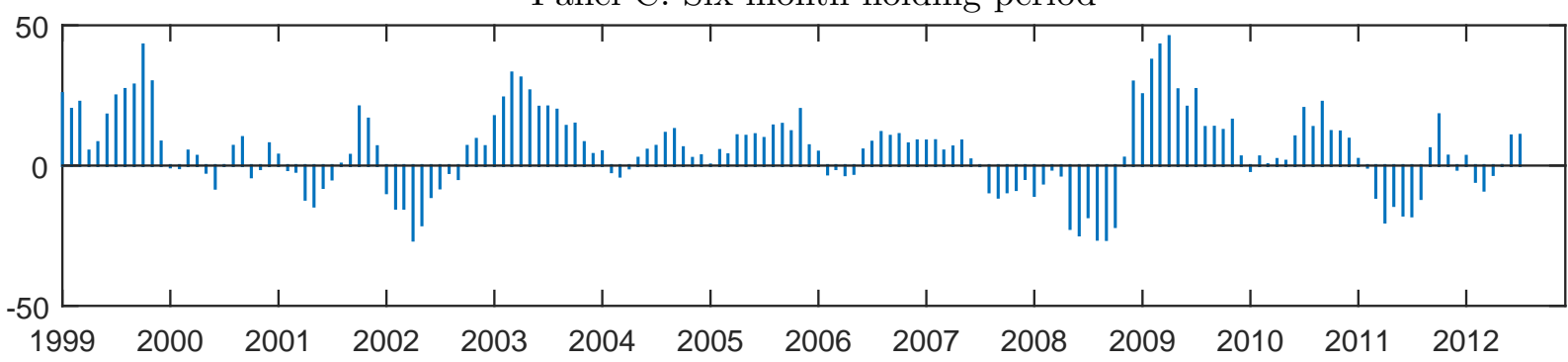

Fig. 2. Time series of the low-minus-high MES portfolio returns across different holding periods (January 1999 to December 2012). This figure plots the low-minus-high MES portfolio returns for periods of one (Panel A), three (Panel B), and six months (Panel C) after portfolio formation. For example, Panel C plots the six-month cumulative return for the low-minus-high MES portfolio while keeping the funds fixed for six months and the portfolio is re-formed each month. 